
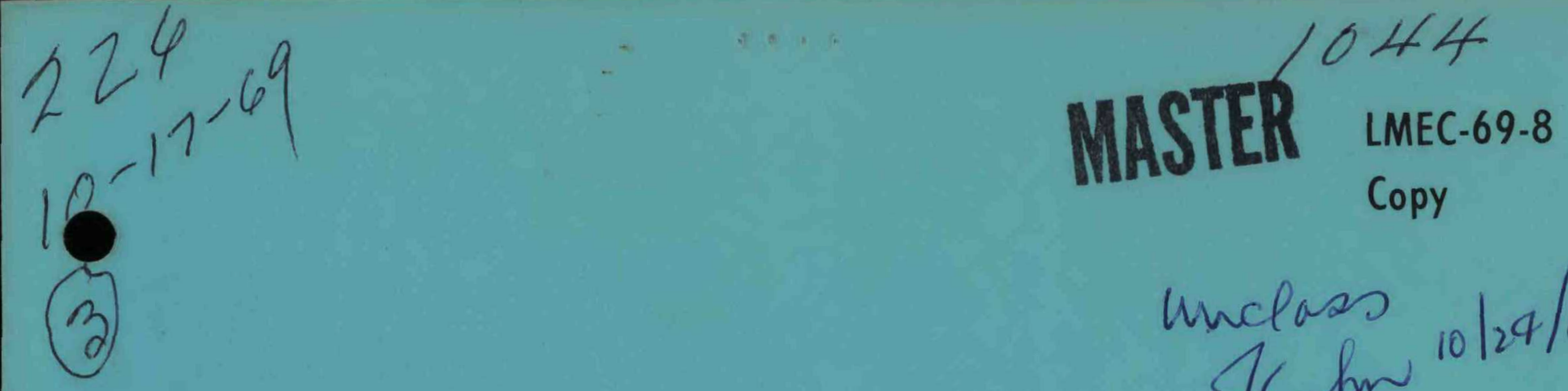

\title{
Bayesian Statistical Model Theory for Mechanical Systems
}

$A E C$ Research and Development Report

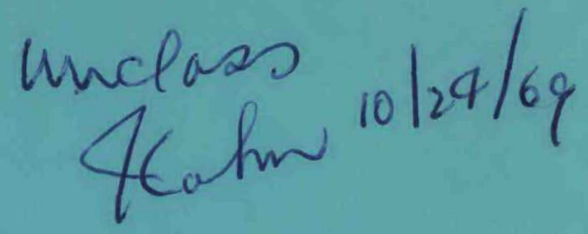

AEC Research and Development Report

Liquid Metal Engineering Center

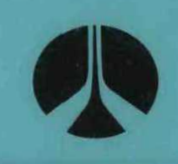
Operated for

the U.S. Atomic Energy Commission by Atomics International 


\section{DISCLAIMER}

This report was prepared as an account of work sponsored by an agency of the United States Government. Neither the United States Government nor any agency Thereof, nor any of their employees, makes any warranty, express or implied, or assumes any legal liability or responsibility for the accuracy, completeness, or usefulness of any information, apparatus, product, or process disclosed, or represents that its use would not infringe privately owned rights. Reference herein to any specific commercial product, process, or service by trade name, trademark, manufacturer, or otherwise does not necessarily constitute or imply its endorsement, recommendation, or favoring by the United States Government or any agency thereof. The views and opinions of authors expressed herein do not necessarily state or reflect those of the United States Government or any agency thereof. 


\section{DISCLAIMER}

Portions of this document may be illegible in electronic image products. Images are produced from the best available original document. 


\section{LEGAL NOTICE}

This report was prepared as an account of Government sponsored work. Neither the United States, nor the Commission, nor any person acting on behalf of the Commission:

A. Makes any warranty or representation, express or implied, with respect to the accuracy, completeness, or usefulness of the information contained in this report, or that the use of any information, apparatus, method, or process disclosed in this report may not infringe privately owned rights; or

B. Assumes any liabilities with respect to the use of, or for damages resulting from the use of information, apparatus, method, or process disclosed in this report.

As used in the above, "person acting on behalf of the Commission" includes any employee or contractor of the Commission, or employee of such contractor, to the extent that such employee or contractor of the Commission, or employee of such contractor prepares, disseminates, or provides access to, any information pursuant to his employment or contract with the Commission, or his employment with such contractor.

Printed in the United States of America Available from

Clearinghouse for Federal Scientific and Technical Information National Bureau of Standards, U.S. Department of Commerce Springfield, Virginia 22151

Price: Printed Copy $\$ 3.00$; Microfiche $\$ 0.65$ 
LMEC-69-8

General, Miscellaneous, and Progress Reports

\title{
Bayesian Statistical Model Theory for Mechanical Systems
}

\author{
By \\ J. P. Walter
}
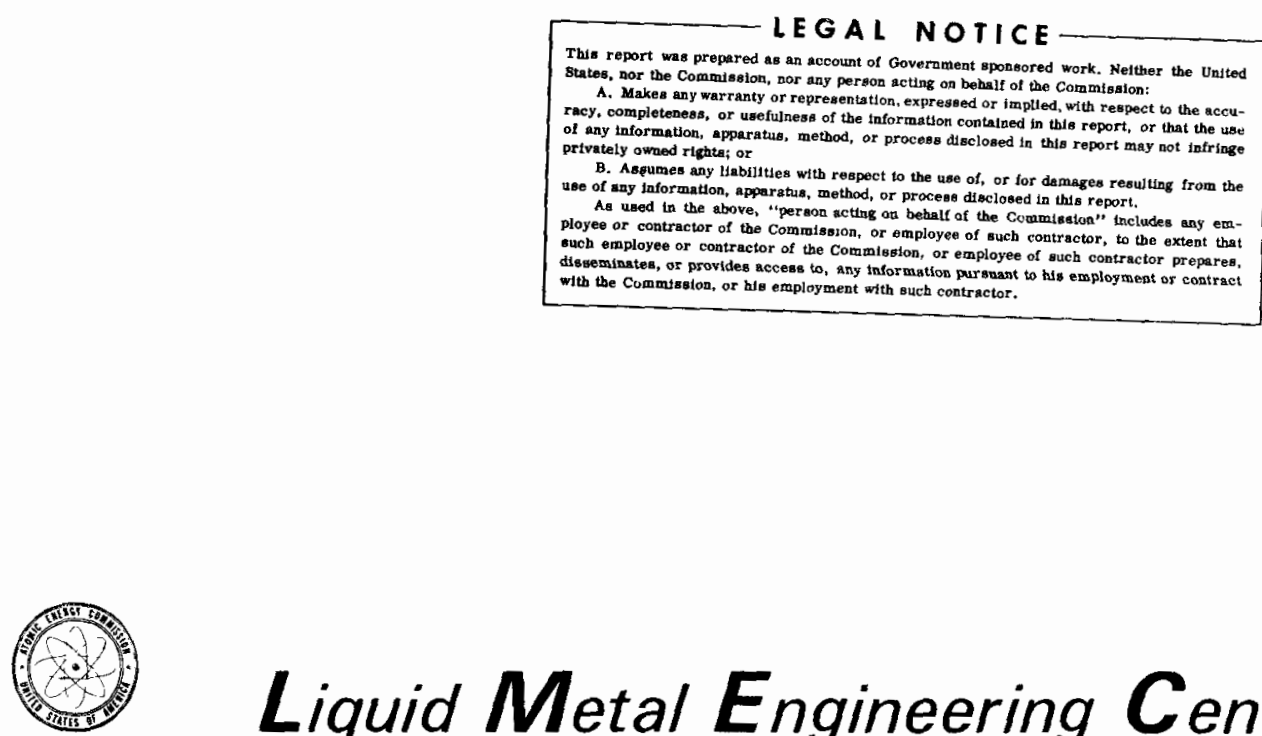

\section{Liquid Metal Engineering Center Operated for \\ the U.S. Atomic Energy Commission by Atomics International \\ A Division of North American Rockwell Corporation}

Contract: AT(04-3)-700

issued: AUG 311969 
DISTRIBUTION

This report has been distributed according to the category "General, Miscellaneous, and Progress Reports" as given in "Standard Distribution Lists for Unclassified Scientific and Technical Reports," TID-4500.

\section{ACKNOWLEDGMENT}

For aid, encouragement, and advice, the author is sincerely grateful to Mr. Charles W. Griffin, LMEC; Dr. Marvin H. Hammond, Institute for Defense Analysis; Dr. Nancy Mann, Rocketdyne Division of North American Rockwell Corporation; Mr. Bruce D. O'Reilly, Sr., Atomics International Division of North American Rockwell Corporation; Dr. John Richardson, Dr. Jerome Spanier, and Dr. Jack Zimmerman, North American Rockwell Science Center; and Mr. Virgil G. Trice, Argonne National Laboratory. 


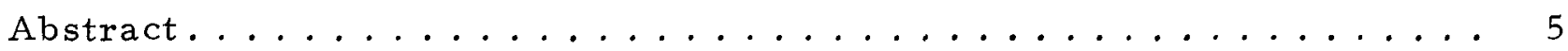

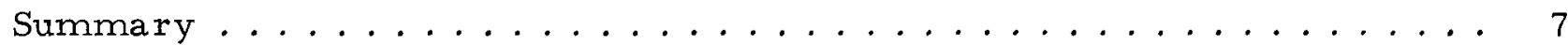

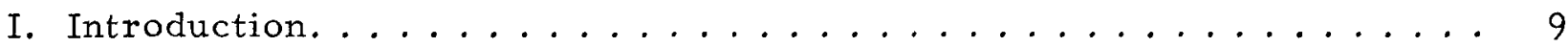

II. Essential Requirements of an Experiment Scheduling System...... 11

A. Starting Rules ......................... 11

B. Transition Rules . . . . . . . . . . . . . . . . . 12

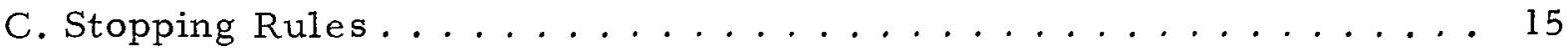

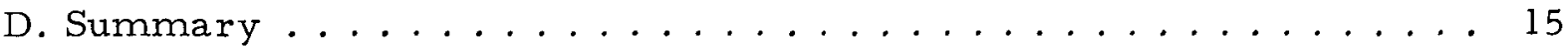

III. Desirable Properties for a Sequence of Experiments . . . . . . . . 17

IV. Performance: Information Gained Versus Cost of Experimentation . . 19

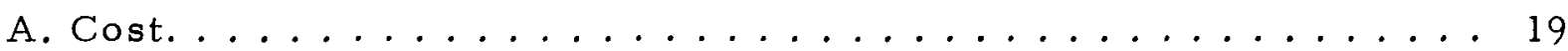

B. Information Gained Through Experimentation ........... 21

1. Information Gained Based on Shannon's Entropy Function . . . . 21

2. Information Based on the Entropy of a Continuous Probability

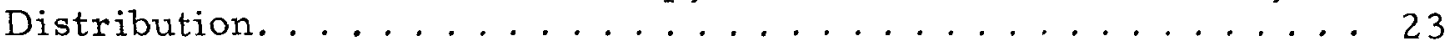

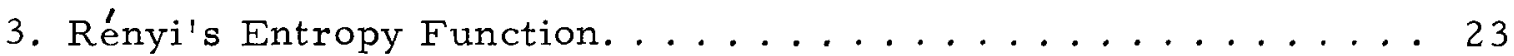

4. Lindley's Measure of Information Gained by an Experiment. . . 24

5. Information Gained as a Gain of Precision . . . . . . . . . 25

C. Kullback's Measure of Discrepancy Between Distributions. . . . . 29

D. Well-Behavedness of Information Gained . . . . . . . . . . . 30

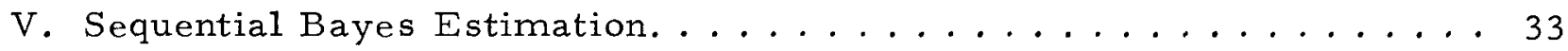

A. Relationship of Prior and Posterior Density Functions . . . . . . 33

B. Natural Conjugate Bayes Densities ................ 33

C. Advantages of Sequential Bayes Estimation . . . . . . . . . 37

D. Disadvantages of Sequential Bayes Estimation . . . . . . . . 37

VI. Adaptive Sequential Bayes Estimation . . . . . . . . . . . . 39

A. Varying the "Credence" of the Prior Estimate........... 39

B. Varying the Density Known to be Pearsonian . . . . . . . . . . 40

C. Estimation of the Density Function as a Random Variable . . . . . 40

VII. Pattern Recognition Approach. . . . . . . . . . . . . . 43

VIII. Dynamic Programming Approach to Sequential Bayes Estimation . . . 45

A. Description of the Method . . . . . . . . . . . . 45

B. Proof of Dynamic Programming Procedure. . . . . . . . . . . 48 


\section{CONTENTS}

Page

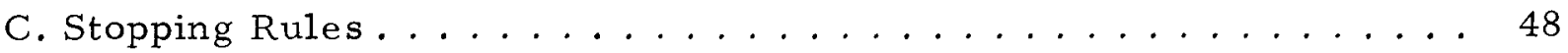

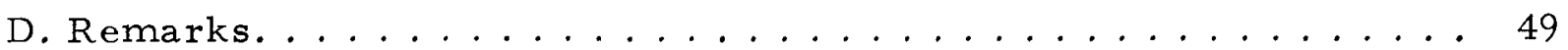

IX. Conclusions and Recommendations ................ 5 I

Appendixes

A. Simulation Study for Point Estimation . . . . . . . . . 53

B. An Example of Bayesian Fitting of Polynomial Regression Curves . 67

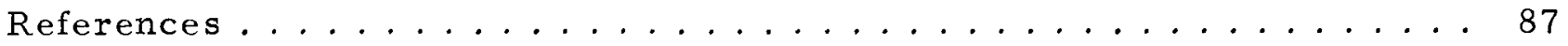

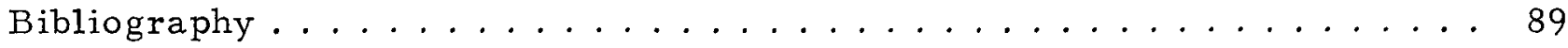

\section{TABLES}

A-1 True Variance $=0.1 \ldots \ldots \ldots \ldots \ldots$

A-2 True Variance $=1 \ldots \ldots \ldots \ldots$

A-3 True Variance $=10 \ldots \ldots \ldots 1$

\section{FIGURES}

B-1 Measurement Sequencing Algorithm. . . . . . . . . . . . . . 72

B-2 Algorithm to Compute Weibull Coefficients . . . . . . . . . 73

B-3 First Stage $(3$ points $) \ldots \ldots \ldots \ldots \ldots$

B-4 Second Stage $(4$ points $) \ldots \ldots \ldots \ldots$

B-5 Third Stage $(5$ points $) \ldots \ldots \ldots \ldots$

B-6 Fourth Stage $(6$ points $) \ldots \ldots \ldots \ldots 1$

B-7 Fifth Stage $(7$ points $) \ldots \ldots \ldots \ldots \ldots$

B-8 Sixth Stage $(8$ points $) \ldots \ldots \ldots \ldots \ldots$

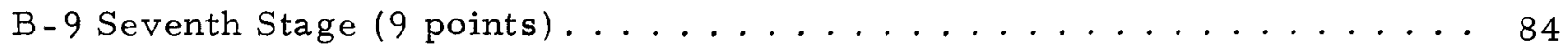




\begin{abstract}
The experiment sequencing problem is restated as an optimization problem, the object of which is to maximize information gained from experimentation; numerous candidates for an information gain function are introduced.

Sequential Bayes estimation procedures are discussed for both parametric and empirical applications, where the methods of Hammond, Richardson, and Rutherford are presented. Examples include: (1) an instance of sequential Bayes point estimation on the basis of computer-simulated Gaussian data, and (2) implementation of a technique for actual metallurgical experimental data, the errors of which are postulated to be Weibull-distributed.
\end{abstract}

LMEC-69-8 
. 


\section{SUMMARY}

An elementary study was conducted to determine requirements and methods for the optimal sequencing of experimental measurements. To incorporate desirable properties into the starting, transition, and stopping rules, a cost/ effectiveness model is employed. Thus the measurement sequencing problem is treated as an optimization problem, where the measure of effectiveness is the derived function "information gained from experimentation" and the purpose of the algorithm is to minimize the ratio whose numerator is cost and whose denominator is the information gained. Several candidates for information-gain functions are introduced; the entropy functions of Shannon and Rényi are discussed, as well as Lindley's information-gain function and some general regularity criteria for information-gain functions.

Common-sense investigation of some hypothetical experimental environments demonstrates the desirability of using prior knowledge in the sequencing of measurements. The use of prior information and Bayesian techniques are thus explored at various levels.

Using computer-simulated normal sample values, a modified sequential Bayes point estimation technique is compared with standard (NCBD) ${ }^{*}$ Bayes and maximum likelihood estimation. A further refinement is provided in an elegant dynamic programming procedure by Dr. J. M. Richardson for the sequencing of measurements that are linearly related and normally distributed.

For the case of sample data having an unknown probability density, several approaches are reviewed, including Hammond's (discretized) pattern recognition synthesis, the estimation of probability density functions as actual random variables, and the empirical Bayes technique by Rutherford and Krutchkoff that fits data points to a Pearson curve.

The study ends with an example of the application of a recursive algorithm for sequencing measurements of metallurgical test parameters, where it is assumed that the experimental error follows a Weibull distribution.

*Natural Conjugate Bayes Density 
-

○ 


\section{INTRODUCTION}

A commonplace task in an engineering study is the construction of a graph, an equation, or several equations to illustrate the functional relationship of two or more physical quantities based upon a minimum of experimental data. For small sample sizes, it is difficult to obtain significant results from an experimental sequence that has been completely specified in advance. When vast differences between initial assumptions and experimental results appear during the course of experimentation, it is difficult to justify adherence to the preplanned arrangement of experiments which may be a Latin square, factorial, or balanced lattice design. When a specific experimental design with a designated statistical confidence criterion has undersubstantiated, oversubstantiated, underrejected, or overrejected some estimate or hypothesis, project time and cost constraints are less likely to be upheld. This report is motivated by the need for a method by which an investigator may systematically revise his plan of experimentation or weigh the direction of his statistical analysis methodology on the basis of his most recent results. 
-

1 


\section{ESSENTIAL REQUIREMENTS OF AN EXPERIMENT SCHEDULING SYSTEM}

Just like any other sequence of events, a program of experiments must somehow be initiated, continued in a goal-oriented manner, and terminated. An elementary discussion of starting, transition, and stopping rules is presented in this section. While this presentation may be readily generalized to cover an arbitrary number of variables, the present discourse is (for the sake of simplicity) restricted to the case of two variables.

\section{A. STARTING RULES}

The selection of the first of a series of experiments is largely dependent upon prior knowledge (the suspected outcome) of the series. When the physical laws governing experimental outcomes are relatively well-known, the investigator is likely to prefer a specific set of conditions for the first experiment. For example, consider the case of a group of particles whose kinetic energy is suspected to influence the likelihood of surpassing some potential barrier. Assume that the investigator controls some measure of the kinetic energy and observes the potential state of a proportion of the particles, to develop a graph as given below.

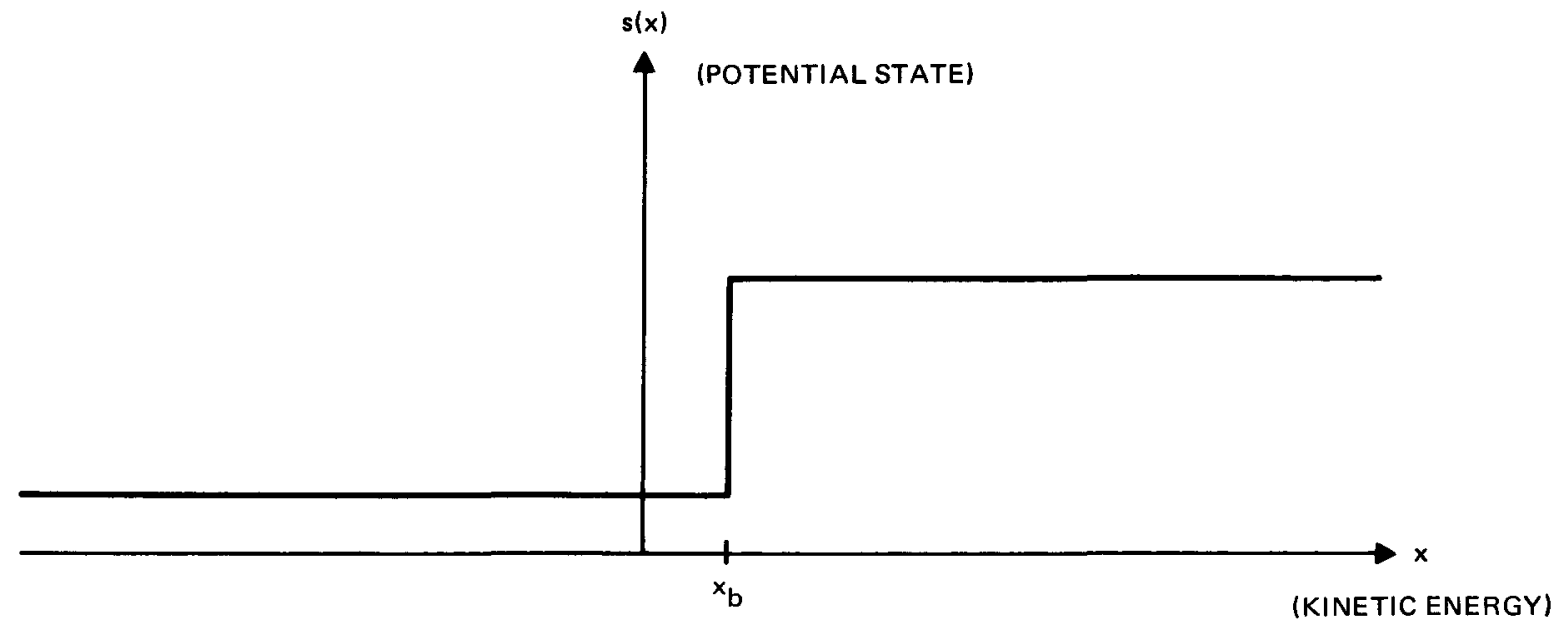

For the first experiment, the investigator is apt to specify an $x$ as close as possible to the suspected location of $\mathrm{x}_{\mathrm{b}}$. 
In the case where neither theory nor the investigator's judgment predicts $x_{b}$, the initial choice of $x$ may be of little significance; a point such as the midrange of available values for $x$ may be selected.

\section{B. TRANSITION RULES}

Once a sequence of experiments has been started, it is usually true that some choices of experiments offer more useful results than others. Here, four ways to choose the next experiment are considered: (1) systematic sampling, (2) random sampling, (3) stratified sampling, and (4) sampling influenced by recent experimental results.

Systematic sampling is frequently employed simply because it is easier. For example, assume that the outcomes of a set of experiments are dependent upon the position of an ultra-precise optical platform. Once all the components of the apparatus have been assembled, it is relatively simple to begin experimentation at the greatest distance, systematically advance the position of the platform by, for example, 10 angstroms after each measurement, and continue sweeping the full range of positions until enough data have been gathered. The transition rule for systematic sampling would be to change the controllable parameter by a fixed amount, depending upon the very last (and thus the very first) experiment. Note that this is a case where the major cost of the experimental program has been incurred prior to the first experiment. The incremental cost of each experiment is so relatively small that the effort expended in accumulating a histogram of almost any sample may be negligible.

Random sampling is typically used where the outcome of the sequence of trials is assumed to be statistically independent of the order in which the trials are made. Consider now a set of wear measurements (experiments) made on teeth of a gear. Assume that this gear is mounted on a shaft suspended on ball bearings and that the gear has a total of 180 teeth. By symmetry, it can be argued that, at a given time, each tooth of the gear should be worn just as much as any other tooth. Thus, the investigator may well be justified in measuring the wear on randomly selected gear teeth, even if in some cases the same tooth is reselected (and particularly if access to the gear is difficult). Thus, the transition rule for random sampling would be to ignore the accumulated history of controlled and observed variables, merely choosing a value for the controlled 
variable at random. The investigator may even try to avoid regular patterns of selection, although the possibility of repeating a given measurement should not be eliminated.

Stratified sampling is used when the population sampled is decomposable into recognizable subpopulations of known proportion. Say that a piping system was constructed with two kinds of valves and that there are equal numbers of valves of each type. If the mortality of the valve population is to be determined by sampling just a small proportion, the sample should contain equal numbers of valves of each type. A transition rule for stratified sampling would be to choose the next measurement so that the proportion of elements from each subpopulation is represented in the sample. $(1)^{*}$

It is also possible to construct transition rules which take into account the experimental results. That is, the selection of the controlled variable for the next measurement is dependent upon the values of both the controlled variable and the observed variable over previous measurements. Assume that there is a requirement to measure the index of refraction, I, of a (translucent) fluid passing through a transparent pipe at a controllable velocity, $v$, and that, at most, ten measurements may be made. Say that refraction measurements have been made for three different flow rates, as shown below.

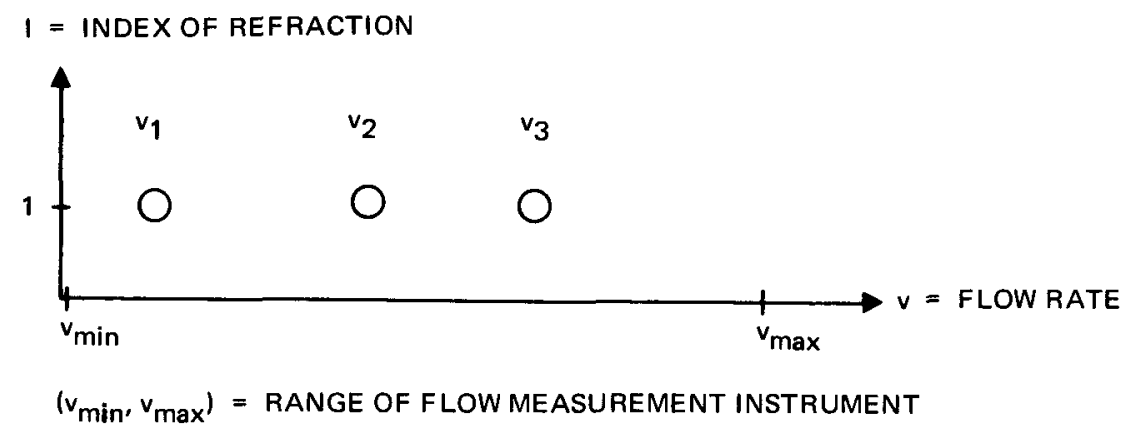

*Superscripts refer to the References listed at the end of this report. 
The investigator, noting that $I_{1}, I_{2}$, and $I_{3}$ are nearly the same, would be most apt to choose $v_{4}$ near $v_{\max }$ (or even near $v_{\text {min }}$ ) in order to detect changes in I due to changes in $v$. The transition rule would be to pick the value of the controlled variable associated with the greatest uncertainty in the observed variable.*

Assume that numerous specimens of a piece of equipment are tested at various temperatures to determine compliance with a reliability requirement. By timing periods between malfunctions, the analyst arrives at a failure rate that is used to compute the reliability of the equipment. After four sets of experiments, the following graph is obtained:

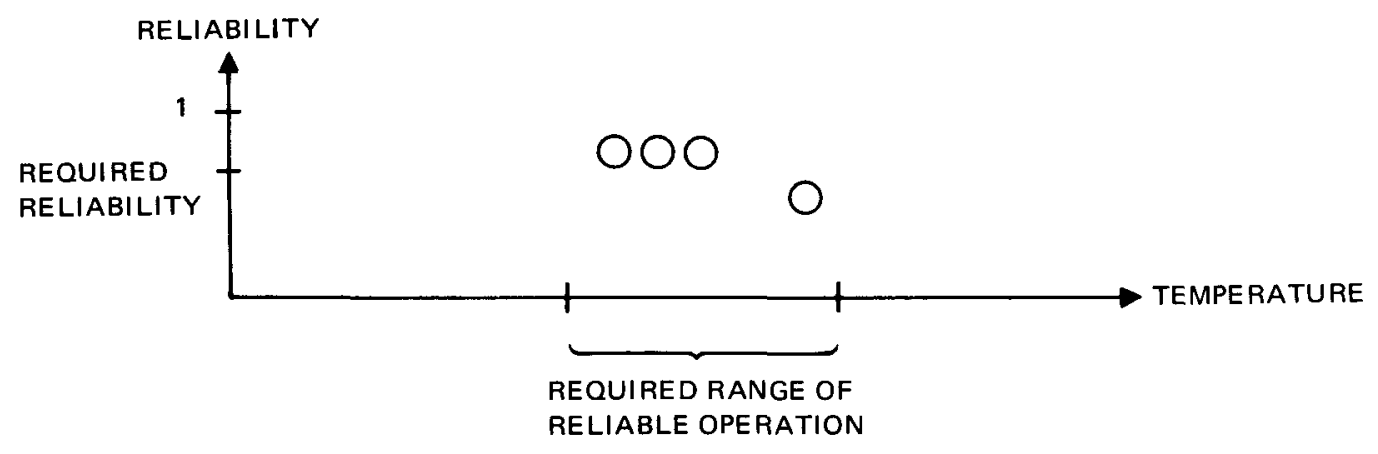

The apparent downward trend clearly indicates that, given no prior indication of expected reliability, the best choice for the next set of experiments should use the maximum required temperature.

Note that if the analyst is assumed to be just starting his experimental program and has been told that the equipment is probably sensitive to high temperature, he would choose the maximum required temperature for the very first set of experiments. As a practical matter, then, the person who is interested in minimizing the number of measurements needed to establish some estimate or hypothesis is well advised to: (1) use earlier test data to select future measurements, and (2) consider available pretest information even before making the first measurement.

*If experimental error (measured here by the repeatability of the refractometer) were very small, a Fibonacci search as in Wilde(2) would probably be used. 


\section{STOPPING RULES}

Once a given method for scheduling experiments has a starting rule and a transition rule, the remaining essential requirement is a stopping rule. Various criteria may be used to determine when to halt a sequence of experiments.

Budget constraints place an upper bound on the number of experiments and may have a very drastic effect when the incremental cost of each experiment is high. Time constraints, also, may curtail experimentation if the sequence of experiments has been fitted into a tight schedule.

In addition to stopping because of time and budget limitations, the re is also the possibility that the sequence of experiments has fulfilled its precision requirements before both time and funds are exhausted. Say that the controlled variable and the observed variable fulfill a linear relationship and that a straight line has been fitted to the first few data points as depicted below.

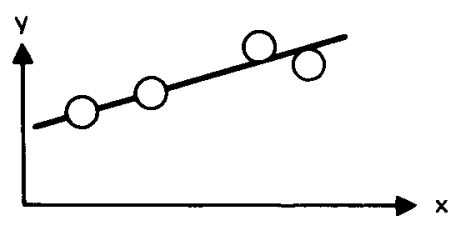

If every data point, after the first few, approaches the previously fitted line within an acceptable precision, then it may be reasonably assumed that the pre-cision goal of the sequence of experiments has been satisfied and that experimentation may be halted.*

\section{SUMMARY}

It should be apparent that this description of an experiment scheduling system in terms of starting, transition, and stopping rules is quite general; the selection of these rules is obviously dependent upon both the nature of the experiments used and the state of knowledge of the investigator. In the next section,

\footnotetext{
*In the regression $\mathrm{Y}=\mathrm{a}+\mathrm{bx}$, if $\mathrm{x}$ and $\mathrm{Y}$ are normal, then $\mathrm{a}$ is normal and $\mathrm{b}$ is $t$-distributed with $n-2$ degrees of freedom, where $n$ data points are used. (3)
} 
some desirable features of an experiment sequencing algorithm are presented so that in further sections an attempt can be made to propose ways in which appropriate starting, transition, and stcpping rules may be chosen. It is hoped that this very general approach will prove worthwhile, as the author would eventually like to generalize this discussion to the level of rules (covering entire classes of experiments) rather than generating hypothetical details and data whenever considering a new sequencing method. 


\section{DESIRABLE PROPERTIES FOR A SEOUENCE OF EXPERIMENTS}

Although not all criteria for the selection of starting, transition, and stopping rules are known prior to the actual hardware confrontation, there are still some very general desirable features which the author would like to incorporate into a scheduling algorithm for experiments of all kinds. All experimental environments are conditioned by constraints of time, budget, tolerable error, and lack of prior knowledge. Thus, the following desiderata may be identified as those properties which would be desirable to build into the sequencing algorithm in the actual process of selecting starting, transition, and stopping rules:

1) All available pertinent information must be usable for guidance of subsequent experiments.

2) The likelihood of repeating a given experiment should be small (minimize incremental cost and time).

3) The total number of experiments should be minimized (minimize total cost and time).

4) To maintain a specified precision, there must be a tractable and reliable method for examining the trustworthiness of the data generated by the experimental sequence.

Recalling that the experiment sequencing problem considered here has the objective of constructing an approximate functional relationship among the controlled and observed variables, a method will be sought by which the starting, transition, and stopping rules can be selected so that they produce a program of experiments that exhibits the aforementioned desiderata.

Several modern mathematical methods treat aspects of the experiment sequencing problem under a variety of conditions. In the following sections, some approaches will be considered which appear to be most useful. 







\section{PERFORMANCE: INFORMATION GAINED VERSUS COST OF EXPERIMENTATION}

Although the desired properties of a sequence of experiments can be enumerated and it can be stated that the starting, transition, and stopping rules should describe the method which determines the best sequence, a quantitative objective function must first be developed. This function, whose increase or decrease should be sensitive to the rules chosen, serves as an index of performance. The approach chosen here shall be that of a cost/effectiveness model, where the effectiveness of the experiment sequencing system is some measure of the information gained through experimentation. If cost/effectiveness is taken to be the ratio whose numerator is accumulated total cost and whose denominator is a measure of information gained, then the problem of experiment sequencing is the problem of selecting rules for starting, transition, and stopping such that the cost/effectiveness ratio is minimized. An advantage of this approach is that, if cost data are unknown or suspected to be misleadingly erroneous, minimization of the reciprocal of the information gained will maximize information gained.

\section{A. $\operatorname{cosT}$}

After $n$ experiments, the total cost, $C_{n}$, is the sum of the incremental costs, denoted $c(x)$. The term $c(x)$ is a function of the controlled variable(s) and, for a single controlled variable $x_{1}$, is a two-dimensional curve as indicated below:

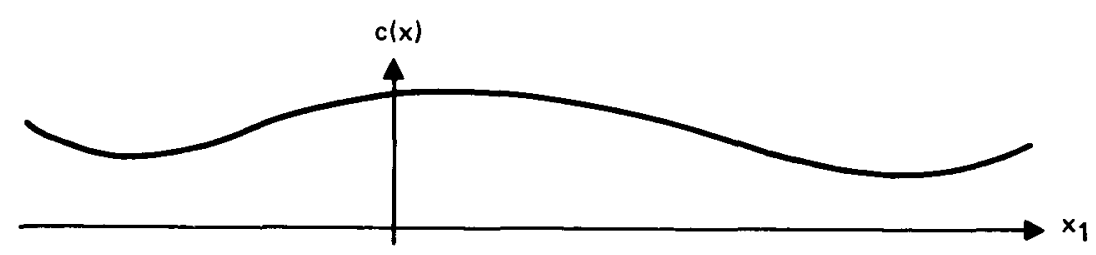


For the case of a series of experiments in which only one control variable is being varied in each experiment, a unique $x_{i}$ is chosen, so that the total cost after the $\mathrm{n}^{\text {th }}$ experiment is:

$$
\mathrm{C}_{\mathrm{n}}=\sum_{i=1}^{\mathrm{n}} \mathrm{c}\left(\mathrm{x}_{\mathrm{i}}\right)
$$

where the $x_{i}$ has no intrinsic order. In case each experiment is equally costly,

$$
\frac{d}{d x} c(x)=0, \text { all } x
$$

The total cost is then:

$$
\mathrm{C}_{\mathrm{n}}=\sum_{i=1}^{\mathrm{n}} \mathrm{c}\left(\mathrm{x}_{\mathrm{i}}\right)=\mathrm{nC}(\mathrm{x})
$$

Cost functions are easily generalized for an arbitrary number of controlled variables. For experimentation costs that are random variables, $c\left(x_{i}\right)$ is an outcome of the experiment; cost is then an observed variable and is estimated as the other observed variable(s). Three remarks are in order:

1) For constant incremental cost, minimization of total cost is tantamount to minimization of the total number of experiments.

2) Before the first experiment (when presumably the choice of experiments depends on the investigator's prediction of the outcome), the accumulated total cost resulting from experimentation is zero, indicating that the selection of the values for the controlled variables is based on the amount of information which is expected to be gained.

3) Constant incremental cost implies that the minimum cost-effectiveness arises from maximum information gained. 


\section{B. INFORMATION GAINED THROUGH EXPERIMENTATION}

A formal description must now be constructed for what is meant by using experiments to gain information. Before making any dramatic conclusions, some earlier results will be indicated.

Discussion in this section, which centers on measures of information gained, is predicated on knowledge of the probability density function governing the statistical behavior of the observed variable(s). Density functions for production of results of experiments that have never been conducted previously can only be approximations (guesses). Later in this report, references will be made to procedures for the sequential approximation of density functions of the observed variable(s) to decide upon rules for obtaining the best sequence of values for the controlled variable(s); the measure of information gained and the procedure for approximation of densities are thus interdependent.

Shannon's entropy function is used as a starting point - not for specific use to determine information gained by experimentation, but rather as an initial building block for the purpose of developing mathematical arguments leading to more useful and appropriate information gain functions.

1. Information Gained Based on Shannon's Entropy Function

Given a known finite discrete probability function $\mathrm{P}$,

$$
P=\left(p_{1}, p_{2}, \ldots, p_{n}\right), p_{i}=\operatorname{Prob}\left(Y=Y_{i}\right)
$$

where $Y$ is the experimental output and $Y_{i}$ is the discrete value to which a known probability is attached.

The average self-information, or entropy, of $P$ as defined by Shannon is (4)

$$
\begin{aligned}
H(P) & =H\left(p_{1}, p_{2}, \ldots, p_{n}\right) \\
& =\sum_{k=1}^{n} p_{k} \log _{2} \frac{1}{p_{k}} \\
& =\sum_{k=1}^{n}-p_{k} \log _{2} p_{k} .
\end{aligned}
$$


The term $H(P)$ is a measure of the uncertainty of $Y$ in the sense that $H(P)$ is maximized when all the $p_{i}$ values are equal $\left(p_{i}=1 / n, i=1,2, \ldots, n\right)$ and $H(P)$ is minimized whenever some $p_{i}=1$. To apply $H(P)$ as an objective function useful in scheduling experiments, a finite number of possible outcomes is assumed; and it is furthermore assumed that the true value of $Y$ being estimated is unique. Then a function of $H(P), G[H(P)]$, is constructed so that $G$ increases when some $p_{i}$ increases past $1 / n$; i.e., as $P\left(Y=Y_{i}\right)$ increases. One such function is

$$
G[H(P)]=\frac{1}{H(P)}
$$

Thus, as some $p_{i}$ approaches 1 , the function, $G[H(P)]$, becomes positively infinite. For a measure of the information which has been gained as a result of experimentation, assume that previous to an experiment the following probability distribution has been obtained:

$$
\begin{gathered}
P^{\prime}=\left(p_{1}^{\prime}, p_{2}^{\prime}, \ldots, p_{n}^{\prime}\right) \quad \text { with entropy } \\
H\left(P^{\prime}\right)=\sum_{k=1}^{n}-p_{k}^{\prime} \log _{2} p_{k}^{\prime}
\end{gathered}
$$

to produce

$$
\mathrm{G}\left[\mathrm{H}\left(\mathrm{P}^{\prime}\right)\right]
$$

Assume that after an experiment, a new distribution is obtained as follows:

$$
\begin{gathered}
\mathrm{p}^{\prime \prime}=\left(\mathrm{p}_{1}^{\prime \prime}, \mathrm{p}_{2}^{\prime \prime}, \ldots, \mathrm{p}_{\mathrm{n}}^{\prime \prime}\right) \text { with entropy } \\
\mathrm{H}\left(\mathrm{P}^{\prime \prime}\right)=-\sum_{\mathrm{k}=1}^{\mathrm{n}} \mathrm{p}_{\mathrm{k}}^{\prime \prime} \log \mathrm{p}_{\mathrm{k}}^{\prime \prime},
\end{gathered}
$$

yielding $G\left[H\left(P^{\prime \prime}\right)\right]$. 
The amount of information gained is then

$$
G\left[H\left(P^{\prime 1}\right)\right]-G\left[H\left(P^{\prime}\right)\right] \text {. }
$$

It is apparent that this choice of $G$ will not save the investigator from any unnecessary experiments, as information gained becomes extremely large for small differences in $p_{i}^{\prime}$ and $p_{i}^{\prime \prime}$ when each is near 1 . While functions of $H(P)$ other than the $G$ which was actually chosen are possible, the desirability of discretizing the possible range of the observed variable, $Y$, for every value of the controlled variable, $X$, is somewhat dubious at this time.

Consistent with the notation of Raiffa and Schlaifer, the prime notation above is meant to indicate a previous condition of the probability functions and is not to be construed as the differentiation operator. $P^{\prime}$ is the density before experimentation, and $P^{\prime \prime}$ applies after experimentation and possible revision of the density.

In this development of the Shannon entropy function, the notion of gaining information by increasing confidence or decreasing variance is not considered and appears difficult to apply. Certainly one requirement for an informationgain function is the logical treatment of the case of increasing confidence, and this aspect is covered later in this report.

2. Information Based on the Entropy of a Continuous Probability Distribution The continuous form of Shannon's entropy function is

$$
H(X)=-\int_{X} \rho(x) \log _{2} \rho(x) d x,
$$

where $\rho(x)$ is the continuous probability density function for $x$. The information gained can be derived in the same manner as in the discrete case above, provided that the density function is given. Further developments of the continuous analog of Shannon's entropy function are discussed later.

\section{Rényi's Entropy Function}

A generalized version of Shannon's entropy function was developed by Renyi in answer to the problem of constructing an entropy function to cover the case of

$$
\text { LMEC - 69-8 }
$$


a composite experiment consisting of two independent experiments. The resulting entropy function ${ }^{(5)}$ is known as entropy of order $\alpha$, and is given as

$$
\mathrm{H}_{\alpha}\left(\mathrm{p}_{1}, \mathrm{p}_{2}, \ldots, \mathrm{p}_{\mathrm{n}}\right)=\frac{1}{1-\alpha} \log _{2}\left(\sum_{\mathrm{k}=1}^{\mathrm{n}} \mathrm{p}_{\mathrm{k}}^{\alpha}\right) \text {, }
$$

for the discrete case. While proper selection of the order parameter, $\alpha$, ought to provide more realistic expressions for information gained, there remains the difficulty of $H$ being highly sensitive to the (probably unknown) probability density function. Further discussion of this entropy function is thus deferred until some methods for approximating density functions have been developed.

4. Lindley's Measure of Information Gained by an Experiment ${ }^{(6)}$

Although the true density function of the observed variables may be unknown at the start of a sequence of experiments, it may still be guessed. Specialists frequently display the capability to accurately forecast outcomes of experiments that have never been previously conducted. Among a community of experts, this prediction skill varies from person to person and from topic to topic, according to individual experience. The initial guess of the probability distribution of the observed variable(s) will be formally defined as the prior distribution. Then the prior information $I_{0}$ with respect to $\theta$, can be defined in a way similar to Shannon's continuous entropy, viz:

$$
I_{0}=\int_{\theta} P(\theta) \log P(\theta) d \theta,
$$

where $\theta$ is an assumed parametric function of the observed data (e.g., $\theta$ is the mean of the population from which the observations are drawn). After the first experiment, the posterior distribution of $\theta$ can be computed, conditioned by the observed data and highly sensitive to the prior distribution. If $Y$ is the 
observed variable, then the amount of information, $I_{1}$, due to the data $Y$ represented by the posterior distribution is

$$
I_{1}=\int_{\theta} p(\theta \mid Y) \log p(\theta \mid Y) d \theta
$$

Then the amount of information gained is

$$
I[p(\theta)]=I_{1}-I_{0}
$$

It must again be emphasized how drastically sensitive this measure (of information gained) is to an erroneous prior distribution. Methods for reducing this sensitivity will be explored later.

\section{Information Gained as a Gain of Precision}

It is also possible to view the gain of information as an increase in precision or, more directly, as a decrease in error. Since the problem of experiment sequencing is also concerned with exror reduction, some examples of measures of precision are provided in the following paragraphs.

a. Measures of Precision of a Point Estimate

(1) Classical Confidence Intervals (Exact Procedure)

In some cases, the statistical behaviour of the quantity being measured is known to be within a class of density functions. Significance of the desired statistic is then easily obtained with a large degree of assurance. For many physical measurements, the Gaussian (normal) density describes the variation of the measured quantity. Here it is a simple matter to compute the confidence limits, for any desired precision, from a set of observed values by means of table look-up. Similarly, there are many other well-known distributions which are tabulated and accessible to the investigator. 


\section{(2) Bayesian Confidence Intervals}

The Bayesian confidence level may be computed by means of the posterior density,

$$
h(\theta \mid x)=\frac{f(\theta) g(x \mid \theta)}{\int_{\theta} f(\theta) g(x \mid \theta) d \theta}=\frac{f(\theta) g(x \mid \theta)}{\sum_{\theta} f(\theta) g(x \mid \theta)},
$$

where

$$
P\left(\theta_{1}<\theta<\theta_{2} \mid x\right)=\int_{\theta_{1}}^{\theta_{2}} h(\theta \mid x) d \theta=\sum_{\substack{\theta<\theta<\theta \\ \min \max }} h(\theta \mid x)
$$

when it is possible to obtain the respective densities.

(3) Sequential Tests of Significance $(7,8)$

Sequential significance tests have been designed to test specific hypotheses about small samples which come from populations about which some characteristics are known. Most common examples of these are:

1) Testing for a difference in mean value when the standard deviation is known (sequential normal curve test)

2) Testing for a difference in mean value when an estimate of the standard deviation is used (Barnard's sequential t-test)

3) Testing for a difference in proportions

4) Testing for a difference in frequency (sequential Poisson test)

5) Testing for a difference in variance.

(4) Distribution-Free Tolerance Regions

Tests devised to determine tolerance regions with a minimum of information about the population are in the field of nonparametric procedures. Some of these are to be found in Walsh! 
b. Measures of Precision for an Approximating Function

Given the data points produced by some set of experiments, it is possible to apply an infinite number of approximating curves to describe the general relationship. It is desired to have a unique approximating function which in some sense minimizes the deviation from a number of data points to a smooth and tractible curve.

RMS Error:

$$
\epsilon_{\mathrm{RMS}}=\left[\frac{1}{\mathrm{n}} \sum_{i=1}^{n}\left(\mathrm{x}_{i}-\hat{x}_{i}\right)^{2}\right]^{1 / 2}
$$

Mean Error:

$$
\epsilon_{M}=\frac{\sum_{i=1}^{n}\left(x_{i}-\hat{x}_{i}\right)}{n}
$$

Mean Absolute Deviation:

$$
\epsilon_{M A D}=\frac{\sum_{i=1}^{n}\left|x_{i}-x_{i}\right|}{n}
$$

Maximum Deviation:

$$
\epsilon_{\max }=\max _{i}\left(\left|x_{i}-\widehat{x}_{i}\right|\right)
$$

Total Deviation:

$$
\epsilon_{\text {total }}=\sum_{i=1}^{n}\left(x_{i}-\hat{x}_{i}\right)
$$


Total Absolute Deviation:

$$
\epsilon_{\text {tad }}=\sum_{i=1}^{n}\left|x_{i}-x_{i}\right|
$$

c. Integral Measures of Error

As available estimates of (experimental) error are themselves prone to error, it is sometimes beneficial to consider only "smoothed" measures of the error which are Integrals ${ }^{*}$ over the range of the controlled variable(s). The examples given below are taken from the literature of control theory; thus, the known variable indicated is time. These integral error expressions for physically realizable systems may be generalized so that the variable of integration could be any controlled variable (a distance, for example, whose range of integration corresponds to the actual available range of distance values).

Integral Squared-Error:

$$
\text { ISE }=\int_{0}^{\infty} \epsilon^{2}(t) d t
$$

Integral of Squared Time Multiplied by Squared Error:

$$
\operatorname{ISTS} E=\int_{0}^{\infty} t^{2} \epsilon^{2}(t) d t
$$

Integral of Time Multiplied by Squared Error:

$$
\operatorname{ITSE}=\int_{0}^{\infty} t \epsilon^{2}(t) d t
$$

*For the discontinuous case, the analogous sum is implied. 


$$
\operatorname{IAE}=\int_{0}^{\infty}|\epsilon| d t
$$

Integral of Time Multiplied by Absolute Value of Error:

$$
\operatorname{ITAE}=\int_{0}^{\infty} t|\epsilon| d t
$$

Integral of Exponentially Weighted Squared Error:

$$
\operatorname{IEXSE}=\int_{0}^{\infty} \exp (-2 k t) \epsilon^{2}(t) d t
$$

Integral of Modified Exponentially Weighted Squared Error:

$$
\operatorname{IMEXSE}=\int_{0}^{\infty}[1-\exp (-2 k t)] \epsilon^{2}(t) d t
$$

C. KULLBACK'S MEASURE OF DISCREPANCY BETWEEN DISTRIBUTIONS At some point in this process of experimentation and using the results of previous experiments to select the next experiment, there arises the problem of choosing among possible density functions. It is thus convenient to include here a measure of discrepancy between distributions, due to Kullback:

$$
I\left(f_{G}, f_{K}^{*}\right)=-\int_{x} f_{G}(x) \log \left[f_{K}^{*}(x) / f_{G}(x)\right] d x,
$$

where $*=$ complex conjugate. 


\section{WELL-BEHAVEDNESS OF INFORMATION GAINED}

Given the approximate density function and sample data, the informationgain function is constructed for the purpose of being searched for a maximum. As has been seen, the form of the information-gain function is not unique. Furthermore, it is possible to derive functions that do indeed increase when the uncertainty of the estimate is decreased, but which have undesirable properties from a numerical, analytic, or even a common-sense point of view. If the notion of maximizing expected gain of information is expected to be useful, it is necessary to impose additional, more specific, constraints on informationgain functions. Note that the usual strong restrictions on entropy functions need not actually be employed here, since: (1) the information-gain function will change with the approximated probability density, and (2) it is not required (or generally desirable) to have maximum information-gain for a Gaussian distribution or for an exponential distribution. The form of the Shannon entropy function is largely a result of the information additivity property,

$$
I(A B)=I(A)+I(B),
$$

and differentiability property, so that

$$
B I^{\prime}(A B)=I^{\prime}(A)
$$

has a unique solution:

$$
I(p)=-\log p
$$

The additivity property might be relaxed and thus other constraints on the derivative of I may be obtained.

Although there are infinitely many choices for constraints on the information-gain function and its derivative, the viewpoint taken here is that ease of interpolation and smoothness are desirable properties for the information-gain 
function based on an approximate density. Given the (probably approximate) density function, the information-gain function selected shall minimize:

$$
\int_{x}\left(I^{1}(x)^{2}+1\right)^{1 / 2} d x
$$

The following must be noted:

1) Although there is a convenient intuitive analogy between the conditional self-information of Fano and the concept here of informationgain conditioned by a given density, the $I(x)$ used here for information-gain is not the same $I(x)$ defining Shannon's self-information. In Shannon's theory, properties of the self-information are assumed and a density function is chosen to maximize average self-information; in the situation here, a density is predicted and an information-gain function was chosen which is hoped to be maximized by choosing the best next experiment.

2) The choice, $I_{\min }(x)$, which minimizes $\int_{x}\left(I^{\prime}(x)^{2}+1\right)^{1 / 2} d x$ favors information-gain functions that tend to be flat and/or monotone, which simplifies the search for the maximum of $I_{\min }(x)$ over $x$. 
-

○ 


\section{SEQUENTIAL BAYES ESTIMATION}

Bayes estimation is concerned with the mapping of a prior probability space into a posterior probability space. This section deals with sequential Bayes estimation for known prior distributions. Later modified forms of sequential Bayes estimation will be considered, where part of the process is the estimation of a distribution function.

\section{A. RELATIONSHIP OF PRIOR AND POSTERIOR DENSITY FUNCTIONS}

Defining the prior density of $\theta$ as $D^{\prime}(\theta)$, and the posterior density as $D^{\prime \prime}(\theta \mid z)$,

$$
D^{\prime \prime}(\theta \mid z)=D^{\prime}(\theta) L(z \mid \theta) N(z)^{(10)},
$$

where $L(z \mid \theta)$ is the likelihood for the experimental outcomes, $z$, conditioned by parameter $\theta$, and $N(z)$ is a normalizing function. Note that for a wide choice of $D^{\prime}(\theta)$, the posterior density function may become rather unwieldy.

\section{B. NATURAL CONJUGATE BAYES DENSITIES}

Tractibility may be vastly improved in the case that the posterior and prior densities are of similar or identical form. Then it is easy to use the posterior density obtained from the result of the previous experiment as a prior density governing the next experiment. For this class of densities, estimates of parameters of the observed variables may be written in the form of recursion relations. The densities having these features of tractibility are known as Natural Conjugate Bayes Densities. Examples of these are provided below. (11)

Bernoulli Distribution:

Probability Density:

$$
P^{X}(1-P)^{1-x} \quad \begin{aligned}
& x=0,1 \\
& 0<P<1
\end{aligned}
$$


Sample Likelihood:

$$
\propto P^{r}(1-P)^{n-r}
$$

Conjugate Prior Density:

$$
f\left(P \mid r^{\prime}, n^{\prime}\right) \propto P^{r^{\prime}-1}(1-P)^{n^{\prime}-r^{\prime}-1}, \quad \begin{aligned}
& 0<P<1 \\
& \\
& n^{\prime}>r^{\prime}>0
\end{aligned}
$$

Posterior Density:

$$
f\left(P \mid r^{\prime \prime}, n^{\prime \prime}\right), \quad \begin{array}{ll}
r^{\prime \prime}=r^{\prime}+r \\
n^{\prime \prime}=n^{\prime}+n
\end{array}
$$

The prior and posterior density each have form of a beta-distributed random variable.

Poisson Distribution:

Probability Density:

$$
\lambda e^{-\lambda x} \quad x \geq 0, \lambda>0
$$

Sample Likelihood:

$$
\text { Proportional to } \lambda^{r} e^{-\lambda t}, \quad t=\sum_{i=1}^{r} x_{i}
$$

Conjugate Prior Density:

$$
f\left(\lambda \mid r^{\prime}, t^{\prime}\right) \propto e^{-\lambda t^{\prime}} \lambda^{r^{\prime}-1} \quad \lambda \geq 0 ; t^{\prime}, r^{\prime}>0
$$


Posterior Density:

$$
f\left(\lambda \mid r^{\prime \prime}, t^{\prime \prime}\right) \quad \begin{aligned}
r^{\prime \prime} & =r^{\prime}+r \\
t^{\prime \prime} & =t^{\prime}+t
\end{aligned}
$$

Both prior and posterior density are gamma-1.

Uniform Distribution:

Probability Density:

$$
1 / \theta, \quad 0 \leq x \leq \theta, \quad \theta>0
$$

Sample Likelihood:

$$
\begin{aligned}
\propto \theta^{-n} u(\theta-M), \quad \text { where } u & =\text { unit step function } \\
M & =\text { estimated mean. }
\end{aligned}
$$

Conjugate Prior Density:

$$
f\left(\theta \mid M^{\prime}, n^{\prime}\right) \propto \theta^{-n^{\prime}} \quad M^{\prime} \geq 0, \theta>0, n^{\prime}>1
$$

Posterior Density:

$$
\begin{aligned}
f\left(\theta \mid M^{\prime \prime}, n^{\prime \prime}\right) & M^{\prime}=\max \left(M^{\prime}, M\right) \\
n^{\prime \prime} & =n^{\prime}+n
\end{aligned}
$$

The hyperbolic distribution governs both the prior and posterior density functions.

\section{Normal Distribution with Unknown Variance:}

Probability Density:

$$
h^{1 / 2}(2 \pi)^{-1 / 2} e^{-1 / 2 h(x-\mu)^{2}}, \quad-\infty<x<\infty,-\infty<\mu<\infty, h>0
$$


Sample Likelihood:

$$
\propto \mathrm{e}^{-1 / 2 \mathrm{~h} v \mathrm{~W}} \mathrm{~h}^{1 / 2 v}, \mathrm{~W}=\frac{1}{v}\left(\mathrm{x}_{\mathrm{i}}-\mu\right)^{2}
$$

Conjugate Prior Density:

$$
f\left(h \mid v^{\prime}, v^{\prime}\right) \propto e^{-1 / 2 h v^{\prime} v^{\prime}} h^{1 / 2 v^{\prime}-1} \quad h>0, v^{\prime}, v^{\prime}>0
$$

Posterior Density:

$$
\begin{aligned}
\mathrm{f}\left(\mathrm{h} \mid \mathrm{v}^{\prime \prime}, v^{\prime \prime}\right), \quad \text { where } v^{\prime \prime} & =v^{\prime}+v, \\
& =\frac{1}{v^{\prime \prime}}\left(v^{\prime} v^{\prime}+\mathrm{VW}\right)
\end{aligned}
$$

The prior and posterior densities are each gamma-2.

Normal Distribution with Unknown Mean:

Probability Density: Same as above.

Sample Likelihood:

$$
e^{-1 / 2 h n(m-\mu)^{2}}
$$

Conjugate Prior Density:

$$
f\left(\mu \mid m^{\prime}, h n^{\prime}\right) \propto e^{-1 / 2 h n^{\prime}\left(\mu-m^{\prime}\right)^{2}} \quad-\infty<\mu<\infty, h>0,-\infty<m^{\prime}<\infty, n^{\prime}>0
$$

Posterior Density:

$$
\begin{aligned}
f\left(\mu \mid n^{\prime \prime}, h n^{\prime \prime}\right), \quad n^{\prime \prime} & =n^{\prime}+n \\
m^{\prime \prime} & =\frac{1}{n^{\prime \prime}}\left(n^{\prime} m^{\prime}+n m\right)
\end{aligned}
$$

The prior and posterior density functions are, as the process density, normal.

Normal Distribution with Both Mean and Variance Unknown:

Probability Density: Same as above.

Sample Likelihood:

$$
\propto h^{1 / 2} e^{-1 / 2 h n(m-\mu)^{2}} h^{1 / 2 \nu} e^{-1 / 2 h \nu v}
$$


Conjugate Prior Density:

$$
\begin{aligned}
& f\left(\mu, h \mid m^{\prime}, v^{\prime}, n^{\prime}, v^{\prime}\right) \propto h^{1 / 2} e^{-1 / 2 h n^{\prime}\left(\mu-m^{\prime}\right)^{2}} h^{1 / 2 \nu^{\prime}-1} e^{-1 / 2 h v^{\prime} v^{\prime}}, \\
& -\infty<\mu<\infty, \quad h>0, \quad-\infty<m^{\prime}<\infty, \quad v^{\prime}, \quad n^{\prime}, \quad v^{\prime}>0
\end{aligned}
$$

Posterior Density:

$$
\begin{aligned}
& \mathrm{f}\left(\mathrm{u}, \mathrm{h} \mid \mathrm{m}^{\prime \prime}, \mathrm{v}^{\prime \prime}, \mathrm{n}^{\prime \prime}, v^{\prime \prime}\right), \\
& \mathrm{n}^{\prime \prime}=\mathrm{n}^{\prime}+\mathrm{n}, \mathrm{m}^{\prime \prime}=\frac{1}{\mathrm{n}^{\prime \prime}}\left(\mathrm{n}^{\prime} \mathrm{m}^{\prime}+\mathrm{nm}\right), \\
& v^{\prime}=v^{\prime}+v+1, \\
& \mathrm{v}^{\prime \prime}=\frac{1}{v^{\prime \prime}}\left[\left(v^{\prime} \mathrm{v}^{\prime}+\mathrm{n}^{\prime}\left(\mathrm{m}^{\prime}\right)^{2}\right)+\left(v \mathrm{v}+\mathrm{n} \mathrm{m}^{2}\right)-\mathrm{n}^{\prime \prime}\left(\mathrm{m}^{\prime \prime}\right)^{2}\right]
\end{aligned}
$$

The prior and posterior density functions are each normal-gamma.

C. ADVANTAGES OF SEQUENTIAL BAYES ESTIMATION ${ }^{(12)}$

1) Sequential Bayes estimates converge to maximum likelihood estimates for large samples.

2) If the prior estimate is close, the experimental data is smoothed and yields a better estimate than classical methods.

3) If the data fits a Natural Conjugate Bayes Density, analysis is very tractable.

D. DISADVANTAGES OF SEQUENTIAL BAYES ESTIMATION

1) For small samples, undue bias may result.

2) The procedure is highly sensitive to the choice of prior distribution. 
0 


\section{ADAPTIVE SEQUENTIAL BAYES ESTIMATION}

In this section three methods are presented by which a sequential Bayes estimation procedure is enabled to modify the application of the prior density.

\section{A. VARYING THE "CREDENCE" OF THE PRIOR ESTIMATE}

Although the smoothing capability offered by sequential Bayes estimation is a distinct benefit to the accuracy of the estimate when the prior estimate is good and the experimental error is relatively high, badly biased estimates must be anticipated in the case that the prior estimate is bad. In the latter case, the maximum likelihood estimate (MLE) is almost always better. Thus, it would be desirable to have a method that would provide the benefits of increased accuracy and data smoothing when the prior estimate is close, and at the same time avoid the necessity of relying too heavily on the prior estimate in case it happens to be poor. That is, it is desirable to attach a weighting function to the prior estimate so that the relative importance of the prior estimate:

(1) increases when the prior estimate appears to correctly predict the data and

(2) decreases when the prior estimate appears to predict wrong values. If a parameter of a known distribution is being estimated, then the weighted estimate for $\theta$ is

$$
\hat{\theta}_{\mathrm{W}}=\mathrm{b} \hat{\theta}_{\text {Bayes }}+(1-\mathrm{b}) \hat{\theta}_{\mathrm{MLE}}
$$

where $\hat{\theta}_{\text {Bayes }}$ is the Bayes estimate of $\theta$ and $\hat{\theta}_{M L E}$ is the maximum likelihood estimate of $\theta$. For a large class of densities, as the sample size tends toward infinity:

1) The maximum likelihood estimate, $\hat{\theta}_{M L E}$, approaches the true $\theta$.

2) The Bayes estimate approaches the maximum likelihood estimate and, therefore, approaches the true $\theta$.

3) The weighted estimate, $\hat{\theta}_{W}$, is a convex combination of two estimates approaching the true $\theta$ and, therefore, approaches the true $\theta$, also.

LMEC - 69-8 
An open question at this point is the calculation of the weighting coefficient, $b$, which is evidently a function of the prior density, the estimate made with respect to that density, and the actual data points observed - but is independent of the stopping rule for the sequence of estimates. The results of a brief simulation study are presented in Appendix A; the process was constructed to estimate the mean of an arbitrary normal population, "sample" values being obtained by the normal random number generator of the IBM Scientific Subroutine Package.

\section{B. VARYING THE DENSITY KNOWN TO BE PEARSONIAN}

Under the condition that the true density function is one that solves Pearson's differential equation,

$$
\frac{d f}{d x}=\frac{(a-x) f}{b_{0}+b_{1} x+b_{2} x^{2}}
$$

very good estimates may be obtained with an empirical Bayes approach developed by Rutherford and Krutchkoff. ${ }^{(13)}$ They approximate the conditional density function,

$$
f_{G}(x \mid \underline{u})=\int f(x \mid \theta) d G(\theta \mid \underline{u})
$$

where $\mathrm{x}$ is the observed random variable, the vector, $\underline{u}=\left(u_{1}, u_{2}, u_{3}, u_{4}\right)$ represents the first four moments of a Pearson distribution, $\theta$ is the required paramete $r$ which is a function of $x$, and $G(\theta \mid \underline{u})$ is the Pearsonian density function approximated by the corresponding sample moments.

\section{ESTIMATION OF THE DENSITY FUNCTION AS A RANDOM VARIABLE}

Using orthogonal polynomials, Kashyap and Blaydon ${ }^{(14)}$ have employed least-squares techniques to approximate probability distribution and density functions, where the approximate distribution is expressed as

$$
\hat{F}(x)=\sum_{i=1}^{n} a_{i} \phi_{i}(x) .
$$


For $n=3, \phi^{\prime} s$ in the form of Laguerre polynomials have produced rather good estimates for the weights $\left(a_{i}\right)$.

Earlier work by Parzen was concerned with constructing classes of approximate density functions, with special regard to estimating the mode of the true density function. (15)

It is felt that the computational disadvantage of increasing the degree of the orthogonal polynomials used for approximating a prior density function used in sequential Bayes estimation would be compensated by a reduction in sample size. With this idea, the following method is proposed, determining: (1) a rule for estimation of the observed variable and (2) a rule for selection of the next experiment in terms of the value of the controlled variable.

Using the most recent approximation of the density, find $I_{\min }(x)$ so that the quantity

$$
\int_{x}\left[1+\left(I^{\prime}(x)\right)^{2}\right]^{1 / 2} d x
$$

is minimized; then choose $x$ so that $I_{\min }(x)$ is maximized over the entire possible range of the controlled variable.

Next conduct an experiment and solve for

$$
F(x)=\sum_{i} a_{i} \phi_{i}(x)
$$

where the weight, $a_{i}$, for $\phi_{i}$ will be decided by the range of data and minimum mean squared error.*

*Numerous possibilities are listed in the NBS Handbook of Mathematical Functions, pp 774-775. 
-

○ 


\section{PATTERN RECOGNITION APPROACH}

Hammond applied the discrete Pontryagin Maximum Principle to the problem of finding the best sequence of measurements in a pattern recognition system containing noise. (16) The performance functional (which is minimized) increases with measurement costs and penalties for incorrect decisions and decreases with the progress made in reaching the true but unknown pattern class.

Bayesian conditioning is achieved by means of a known matrix of conditional probabilities, relating the vector representing the controlled variable(s) to the vector representing parameters of the observed variable(s). By discretizing prior and posterior probability spaces, as well as the sample space, the closure property is assured; any discrete distribution forms a Natural Conjugate Bayes Distribution.

While it might appear that specification of the various costs and conditional probabilities would be difficult, it must be noted that Hammond's use of the Pontryagin maximum principle indicates a profitable and effective approach to the problem of choosing the next measurement. Application of the continuous Pontryagin maximum principle to our problem of finding the best-fitting information-gain function would contribute in two ways: (1) making more effective the search of existing functions, and (2) helping to indicate new functions for information gained through experimentation. 
○ 


\section{A. DESCRIPTION OF THE METHOD}

An interesting approach by Dr. John Richardson exploits the techniques of dynamic programming. The experiment selection process is a multi-stage decision process which is $\mathrm{n}^{\text {th }}$ order Markov, where $\mathrm{n}$ is the number of experiments which have been performed. Selection of the first experiment is achieved through the use of the prior distribution, the second experiment is selected by use of the prior and the first experimental results, etc. The coherence of the dynamic programming approach is immediately apparent, and the resulting algorithm is rather easy to follow. The dynamic programming method is presented here for the case of two linearly related normal random variables.

Prior Probability Density:

$$
P_{0}(a, b, \sigma)
$$

Likelihood for One Experiment:

$$
\mathrm{P}(\mathrm{y} \mid \mathrm{a}, \mathrm{b}, \sigma, \mathrm{x})=\frac{1}{\sigma \sqrt{2 \pi}} \exp \left[-\frac{(\mathrm{y}-\mathrm{a}-\mathrm{bx})^{2}}{2 \sigma^{2}}\right]
$$

The joint probability density for $\mathrm{N}$ experiments, for parameters $a$, $b$, and $\sigma$ is

$$
P\left(y_{N}, a, b, \sigma \mid x_{N}\right)=\prod_{n=1}^{N} P\left(y_{n} \mid a, b, \sigma, x_{n}\right) P(a, b, \sigma),
$$

where:

$$
\begin{array}{ll}
\mathrm{Y}_{\mathrm{N}}=\left\{\mathrm{y}_{\mathrm{n}}\right\}, & 1 \leq \mathrm{n} \leq \mathrm{N}, \quad \text { and } \\
\mathrm{X}_{\mathrm{N}}=\left\{\mathrm{x}_{\mathrm{n}}\right\}, & 1 \leq \mathrm{n} \leq \mathrm{N} .
\end{array}
$$


With $\hat{a}_{N}$ and $\hat{b}_{N}$ estimating the intercept and the slope of the straight line relating $\mathrm{X}$ to $\mathrm{Y}$, a loss function is defined as

$$
C_{N}=(1 / 2) \alpha\left(\hat{a}_{N}-a\right)^{2}+(1 / 2) \beta\left(\hat{b}_{N}-b\right)^{2}
$$

where $\alpha$ and $\beta$ are constants increasing with the importance of error on intercept and slope, respectively. The risk due to a given sequence of experiments is then the expected loss conditioned by $\mathrm{X}_{\mathrm{N}}$, viz.,

$$
R_{N}=E\left(C_{N} \mid X_{N}\right)
$$

according to the joint density, $P\left(y_{N}, a, b, \sigma \mid x_{N}\right)$. For a given prior, $P_{o}(a, b, \sigma)$, the estimates for $a$ and $b$ are functions of the experimental data points, i.e.,

$$
\hat{a}=\hat{a}\left(Y_{N}, X_{N}\right) \text {, and } \hat{b}=\hat{b}\left(Y_{N}, X_{N}\right)
$$

Minimizing the risk over all the policies for determining $a$ and $b$,

$$
\bar{R}_{N}=\underset{\substack{\text { Policies } \\ \text { for a\& } b}}{\operatorname{Min} E\left(C_{N} \mid X_{N}\right)=E\left(\operatorname{Min}_{\hat{a}, \hat{b}} E\left(C_{N} \mid Y_{N}, X_{N}\right) \mid X\right)}
$$

Thus, the optimal (minimum risk) values of $\hat{a}$ and $\hat{b}$ given $Y_{N}$ and $X_{N}$ are

$$
\bar{a}=E\left(a \mid Y_{N}, X_{N}\right) \text {, and } \bar{b}=E\left(b \mid Y_{N}, X_{N}\right) \text {, }
$$

which produce the risk

$$
\bar{R}_{N}=(1 / 2) \alpha E\left\{E\left[(a-\bar{a})^{2} \mid Y_{N}, X_{N}\right] \mid X_{N}\right\}+(1 / 2) \beta E\left\{E\left[(b-\bar{b})^{2} \mid Y_{N}, X_{N}\right] \mid X_{N}\right\}
$$

which depends on $X_{N}$ and $P_{o}(a, b, \sigma)$. 
Assume that $\mathrm{X}_{\mathrm{N}}$ is determined by the policies

$$
\begin{aligned}
& \mathrm{x}_{\mathrm{n}} \quad \text { is a function of } \mathrm{Y}_{\mathrm{N}-1}, \mathrm{X}_{\mathrm{N}-1} \text {; } \\
& \mathrm{x}_{\mathrm{n}+1} \text { is a function of } \mathrm{Y}_{\mathrm{N}}, \mathrm{X}_{\mathrm{N}} \text {; } \\
& \text { - } \\
& \mathrm{x}_{\mathrm{N}} \quad \text { is a function of } \mathrm{Y}_{\mathrm{N}-1}, \mathrm{X}_{\mathrm{N}-1} \text {; and } \\
& \mathrm{x}_{1} \quad \text { is a function of } \mathrm{P}(\mathrm{a}, \mathrm{b}, \sigma) \text { which is given. }
\end{aligned}
$$

Then, defining

$$
\widetilde{\mathrm{R}}_{\mathrm{N}}=\operatorname{Min}_{\substack{\text { policies } \\ \text { for } \mathrm{X}_{\mathrm{N}}}}\left(\overline{\mathrm{R}}_{\mathrm{N}}\right)
$$

it may be seen that $\widetilde{R}_{N}$ is a function of $P(a, b, \sigma)$.

The dynamic programming solution leads to

$$
\widetilde{\mathrm{R}}_{N}[P(a, b, \sigma)]=\operatorname{Min}_{x_{1}} \int_{Y^{\prime}} d_{1} \widetilde{R}_{N-1}\left[P\left(y_{1} \mid a, b, \sigma, x_{1}\right) P(a, b, \sigma)\right] \text {, }
$$

where

$$
\begin{aligned}
& \widetilde{R}_{\mathrm{o}}(P(a, b, \sigma))=(1 / 2) \alpha\left\{\iiint \mathrm{d} a \mathrm{db} d \sigma \mathrm{a}^{2} \mathrm{P}(\mathrm{a}, \mathrm{b}, \sigma)-\frac{\left[\iiint \mathrm{d} \mathrm{a} d \mathrm{~b} d \sigma \mathrm{aP}(\mathrm{a}, \mathrm{b}, \sigma)\right]^{2}}{\iiint \mathrm{d} a \mathrm{db} d \sigma \mathrm{P}(\mathrm{a}, \mathrm{b}, \sigma)}\right\} \\
& +(1 / 2) \beta\left\{\iint d a d b d \sigma b^{2} P(a, b, \sigma)-\frac{\left[\iiint d a d b d \sigma b P(a, b, \sigma)\right]^{2}}{\iiint d a d b d \sigma P(a, b, \sigma)}\right\} \text {. }
\end{aligned}
$$


B. PROOF OF DYNAMIC PROGRAMMING PROCEDURE

Denote

$$
\begin{aligned}
& P_{0}=P_{0}(a, b, \sigma), \text { and } \\
& P_{n}=P\left(y_{n} \mid a, b, \sigma, x_{n}\right),
\end{aligned}
$$

then

$$
\begin{aligned}
& \overline{\mathrm{R}}_{\mathrm{N}}=\int \mathrm{dy_{1 }} \ldots \int \mathrm{dy}_{\mathrm{N}} \mathrm{f}\left(\mathrm{P}_{\mathrm{N}} \ldots \mathrm{P}_{1} \mathrm{P}_{\mathrm{o}}\right) \\
& \widetilde{R}_{N}=\operatorname{Min}_{\substack{x_{1}, \ldots x_{N} \\
\text { policies }}} \int d_{1} \ldots \int d_{1} \ldots y_{N} f\left(P_{N} \ldots P_{1} P_{0}\right) \\
& =\operatorname{Min}_{x_{1}} \int \mathrm{dy}_{1} \ldots \operatorname{Min}_{\mathrm{x}_{\mathrm{N}}} \int \mathrm{dy} \mathrm{N}_{\mathrm{N}} \mathrm{f}\left(\mathrm{P}_{\mathrm{N}} \ldots \mathrm{P}_{1} \mathrm{P}_{\mathrm{O}}\right)
\end{aligned}
$$

and then

$$
\begin{gathered}
\widetilde{R}_{N}\left(P_{0}\right)=\widetilde{R}_{N-1}\left(P_{1} P_{0}\right) \text {, and } \\
\widetilde{R}_{0}\left(P_{0}\right)=f\left(P_{0}\right),
\end{gathered}
$$

and the minimal risk at any stage can be expressed as a function of the prior probability density and every previous measurement.

\section{STOPPING RULES}

The decision to stop experimentation is dependent upon the los function; thus, to limit the number of experiments, the loss function may incorporate the cost of experimentation, as in

$$
C_{N}=(1 / 2) \alpha(\hat{a}-a)^{2}+(1 / 2) \beta(\hat{b}-b)^{2}+\gamma \sum_{n=1}^{N} \nu_{n},
$$


where $\nu_{n}$ is the cost of the $\mathrm{n}^{\text {th }}$ experiment and $\gamma$ is a weighting factor increasing with the importance of cost. The sequence is terminated if

$$
\widetilde{R}_{N}\left(P_{0}\right)-\gamma<\underset{x_{1}}{\operatorname{Min}} \int d_{1} \widetilde{R}_{N-1}\left(P P_{0}\right) ;
$$

i.e., whenever the risk of continuing exceeds the risk of halting experimentation.

D. REMARKS

The dynamic programming approach is well suited to experiment sequencing problems whenever the prior distribution is well known and the risk function may be specified in advance; and, indeed, these must be specified in advance.

The $\mathrm{n}^{\text {th }}$ order Markov property may be relaxed to first order, making the selection of the next $x_{n}$ dependent on the last state only, to simplify computation and enhance tractibility.

The extension of this method to cover arbitrary (and admittedly uncertain) distributions would be desirable. 
-

- 


\section{CONCLUSIONS AND RECOMMENDATIONS}

Bayesian methods offer an efficient and systematic approach for considering pretest data and current test results in the selection of experimental measurements.

The derivation of information-gain functions requires further investigations, where concepts such as the Pontryagin Maximum Principle and Renyi's entropy function could be used to advantage.

Dynamic programming offers a unified and coherent approach to this sequential decision-making problem.

The estimation of probability density functions should be studied, with a view toward decreasing the number of data points now required by this technique. 
- 


\section{APPENDIX A}

\section{SIMULATION STUDY FOR POINT ESTIMATION}

Varying the "Credence" Attached to a Prior Estimate

The prior estimate of the outcome of a sequence of experiments may be viewed as a data point having a nonphysical "cause." It is desired that a system be considered whose input is: (1) some (possibly purely intuitive) prior estimate, and (2) experimental data; the output is an estimate of the true parameters of the physical process being measured. Frequently, engineering estimates are available and severe limitations are placed on the number of measurements; thus, when the prior estimate is close, it is desirable to place a rather strong reliance upon it. Furthermore, when the prior estimate is poor, it is desirable to quickly refute and revise it.

The object here is to measure the extent to which the prior (pre-data) estimate may be relied upon after a few measurements have been made as, for measurements near those for which prior estimates have been found close, it would presumably be possible to reduce the number of measurements required. Thus, the output of the desired system is an estimate, for the true physical parameter, which is a weighted sum of the prior estimate and the sample statistic; the weight attached to the prior estimate is conditioned by the agreement of the prior estimate with results obtained from actual observations.

\section{Digression to Information Gained}

Although at this point in the example a function cannot be identified which could ideally be called an information-gain function, it is still possible to provide a conceptual background for gain of information by experimentation. If the prior estimate differs greatly from the sample parameter and little credence is attached to the prior estimate, then: (1) the experiments have provided a great deal of information (shown the need for considerable revision of the prior estimate), (2) there is diminished reliance on the prior estimate, and (3) experimentation is increased where more information is to be gained. 


\section{Simulation Study}

The following approach was taken:

1) The class of distributions is restricted to normal random variables of unknown mean and unknown variance (i.e., known only by the random number generator Gauss used to simulate experiments, not by the estimation procedure).

2) The required parameter is the mean.

3) Prior estimates of the mean and variable are supplied.

4) Degree of reliance upon the prior mean is measured by a (rational) effective sample size associated with the prior estimate.

5) Effective sample size, before sampling from the random number generator, is arbitrarily selected as one.

6) The weighting coefficient (multiplier) of the initial effective sample size is a measure of the efficiency of the posterior (Bayes) estimate of the mean.

7) The efficiency estimate is the ratio of the maximum likelihood estimate of the variance (conditioned by the maximum likelihood estimate of the mean) and the estimate of the variance conditioned by the Bayes estimate of the mean, viz.,

$$
\xi=\frac{\hat{\sigma}^{2}(\text { mle })}{\hat{\sigma}^{2}(\text { Bayes })},
$$

where

$$
\begin{aligned}
\hat{\sigma}^{2}(\mathrm{mle}) & =\frac{\sum_{i}\left(\mathrm{x}_{i}-\bar{x}\right)^{2}}{n-1}, \\
\bar{x} & =\frac{\sum_{i} x_{i}}{n},
\end{aligned}
$$




$$
\hat{\sigma}^{2}(\text { Bayes })=\frac{\sum_{i}\left[x_{i}-\hat{\mu}(\text { Bayes })\right]^{2}}{n+n_{0}-1}
$$

and

$$
\hat{\mu}(\text { Bayes })=\frac{n \bar{x}+n_{o} \hat{\mu}(\text { prior })}{n+n_{o}} .
$$

8) The modified Bayes estimate of the variance then becomes

$$
\begin{aligned}
\hat{\mu}(\bmod \text {. Bayes }) & =\frac{\left.\mathrm{n} \hat{\mu}(\mathrm{mle})+\xi \mathrm{n}_{\mathrm{o}} \hat{\mu} \text { (Bayes }\right)}{\mathrm{n}+\xi_{\mathrm{o}}}, \text { or } \\
& =\frac{\left.\sum_{i} x_{i}+\xi \mathrm{n}_{\mathrm{o}} \hat{\mu} \text { (Bayes }\right)}{\mathrm{n}+\xi \mathrm{n}_{\mathrm{o}}},
\end{aligned}
$$

where $\mathrm{n}_{\mathrm{O}}$ is arbitrarily selected as $\mathrm{n}_{\mathrm{O}}=1$ and initial $\xi=1$.

Based on assumptions (1) through (8), the FORTRAN program presented on the following pages was written to calculate the relative error due to Bayes, maximum likelihood, and modified Bayes estimates of the mean of a simulated normal population. The sample values were obtained by use of the normal random number generator Gauss. The following is a brief summary of the FORTRAN program:

1) The parameters (true mean and true variance) of the normal density are given to the random number generator; these are assumed unknown to the estimation procedure.

2) A normal random variable is computed by the random number generator.

3) Bayes, maximum likelihood, and modified Bayes estimates for the mean are computed; new Bayes and modified Bayes estimates are implemented by the use of a prior estimated mean. 
// FOR

* ONE WORD INTEEGERS

* IOCS(CARD, TYPEWRITER, KEYBOARD, II32PRINTER, DISK)

*LIST ALT,

C PROGRAM TO STMULATE PARALLEL ESTTMATION OF MEAN OF NORMAL VARIATE,

C USING MAXIMUM LIKEI,IHOOD, STANDARD BAYESIAN, AND MODIFIFD BAYESIAN

C ESTIMATORS. JOHN P. WALTER

DIMENSION $\mathrm{X}(100)$

ASTEP $=1$.

$\mathrm{NAV}=11$

NSAM $=10$

$\mathrm{NVAR}=3$

TVAR $=.01$

VSTEP $=10$.

DO 50 L3 $=1$, NVAR

TVAR $=$ TVAR * VSTEP

EMEAN $=0$.

DO 50 L2 $=1$, NAV

EMEAN $=$ EMEAN + ASTEP * $(-1) * *($ L2 -1$) *($ L2 - I $)$

TMEAN $=0$.

DO $50 \mathrm{LI}=1, \mathrm{NAV}$

TMEAN $=$ TMEAN + ASTEP $*(-I) *(I I-I) *(I I-I)$

ITEM $=325$

ALFAI $=1$.

AMUO = EMEAN

ANO $=1$.

$\mathrm{AN}=\mathrm{ANO}$

AVARI $=0$.

$\mathrm{BNO}=\mathrm{ANO}$

BVARI $=0$.

SUMX $=0$.

VARY $=0$.

WRITE $(3,400)$ EMEAN

WRITE $(3,300)$ TMEAN, TVAR

WRIIE $(3,999)$

ENO $=1$.

DO $20 I=I$, NSAM

$A I=I$

TSD $=$ SQRT (TVAR)

C

CALL GAUSS(ITEM, TSD, TMEAN, EX)

C

$\operatorname{SUNX}=\operatorname{SUN} X+E X$

$X(I)=E X$

$\mathrm{ANU}=\mathrm{AN}$

$A N=A N+1$.

AMUI $=($ ANU * AMUO + EX $) / A N$

$\mathrm{XBAR}=\mathrm{SUMX} / \mathrm{AI}$

LMEC - 69-8 




LMEC-69-8 
4) The relative errors for each of these estimates, with respect to the true mean, are printed.

5) The process is repeated.

$\underline{\text { Results of the Simulation }}$

Before presenting the output data summary, a step-by-step narrative of a sample computer run is provided which corresponds to Reference No. 17 in the abbreviated listing of results (Tables $A-1$ through $A-3$ ). The following is a facsimile of the computer printout for this run:

EST MEAN $=0.00000 \mathrm{E} 00$

TRUE MEAN $=0.50000 \mathrm{E} \mathrm{OI}$

NO OBSERVATION MLE MEAN BAYES MEAN PRIOR WT. MOD BAYES MEAN

$1 \quad 0.42142 \mathrm{E} \mathrm{OI}$

2 $0.49135 \mathrm{E} \mathrm{OI}$

$3 \quad 0.54252 \mathrm{E} \mathrm{OI}$

$4 \quad 0.47494 \mathrm{E}$ OI

$5 \quad 0.28861 \mathrm{E}$ OI

$6 \quad 0.58354 \mathrm{E} 01$

$7 \quad 0.55971 \mathrm{E}$ OI

$80.41712 \mathrm{E} 01$

$9 \quad 0.45580 \mathrm{E} \mathrm{OI}$

$10 \quad 0.57572 \mathrm{E} 01$
$0.42142 \mathrm{E}$ OI $0.45638 \mathrm{E} \mathrm{OI}$ $0.48510 \mathrm{E} \mathrm{OI}$ $0.48256 \mathrm{E} \mathrm{OI}$ $0.44377 \mathrm{E}$ Ol $0.46706 \mathrm{E} \mathrm{OI}$ $0.48030 \mathrm{E}$ OI $0.47240 \mathrm{E}$ OI $0.47055 \mathrm{E} \mathrm{OI}$ $0.48107 \mathrm{E} \mathrm{O1}$
TRUE VARIANCE $=0.10000 \mathrm{E} 01$

$0.21071 \mathrm{E}$ OI $0.10000 \mathrm{E}$ OI

$0.30425 \mathrm{E}$ OI $0.50166 \mathrm{E}-01$

$0.36382 \mathrm{E}$ OI $0.1434 \mathrm{FE} 00$

$0.38604 \mathrm{E}$ ol $0.16697 \mathrm{E} 00$

$0.36980 \mathrm{E}$ OI $0.57864 \mathrm{E} 00$

$0.40034 \mathrm{E}$ ol $0.66839 \mathrm{E} 00$

$0.42026 \mathrm{E}$ Ol $0.70806 \mathrm{E} 00$

$0.41991 \mathrm{E}$ OI $0.74586 \mathrm{E} 00$

$0.42350 \mathrm{E} \mathrm{OI} 0.7651 \mathrm{TE} \mathrm{OO}$

$0.43734 \mathrm{E}$ OI
$0.31607 \mathrm{E} \mathrm{O1}$

$0.45266 \mathrm{E}$ OI

$0.47956 \mathrm{E} \mathrm{OI}$

$0.47869 \mathrm{E}$ 01

$0.43609 \mathrm{E} \mathrm{OI}$

$0.46037 \mathrm{E} \mathrm{OI}$

$0.47478 \mathrm{E} \mathrm{Ol}$

$0.46792 \mathrm{E} \mathrm{OI}$

$0.4668 \mathrm{TE} \mathrm{OI}$

$0.47785 \mathrm{E} \mathrm{OI}$

REL. ERROR FOR MLE $=-0.37846 \mathrm{E}-01$

REL. ERROR FOR BAYES EST $=-0.12531 \mathrm{E} 00$

REL. ERROR FOR MOD. BAYES $=-0.44299 \mathrm{E}-01$

The reader will note that the computer samples from a normal population (random number generator) with a true mean of 5 and a true variance of 1 . The prior estimate (guess) for the mean is zero, with which a sample size of one has been arbitrarily associated. After each measurement (random number) drawn from the random number generator, maximum likelihood and Bayes estimates for the mean are computed as stated previously in assumption (7); then the weighting coefficient, $\xi$, is calculated so that the modified Bayes estimate is realized as indicated in as sumption (8). 
TABLE A-1

TRUE VARIANCE $=0.1$

\begin{tabular}{|c|c|c|c|c|c|}
\hline $\begin{array}{l}\text { Estimated } \\
\text { Mean }\end{array}$ & $\begin{array}{l}\text { True } \\
\text { Mean }\end{array}$ & $\begin{array}{c}\text { MLE } \\
\text { Relative Error }\end{array}$ & $\begin{array}{l}\text { Bayes } \\
\text { Relative Error }\end{array}$ & $\begin{array}{l}\text { Modified Bayes } \\
\text { Relative Error }\end{array}$ & $\begin{array}{c}\text { Reference } \\
\text { No. }\end{array}$ \\
\hline 0 & 0 & -0.266 & -0.242 & -0.264 & 31 \\
\hline 0 & 0 & -0.214 & -0.195 & -0.212 & 32 \\
\hline 0 & -1 & -0.0233 & 0.0698 & -0.0155 & 1 \\
\hline 0 & -1 & -0.145 & -0.0412 & -0.137 & 33 \\
\hline 0 & 1 & -0.0178 & -0.107 & -0.0249 & 2 \\
\hline 0 & 1 & 0.161 & 0.055 & 0.152 & 34 \\
\hline 0 & -2 & -0.0282 & 0.156 & -0.0168 & 3 \\
\hline 0 & -2 & 0.229 & 0.390 & 0.242 & 4 \\
\hline 0 & 2 & 0.00442 & -0.0869 & -0.00267 & 5 \\
\hline 0 & 2 & 0.0462 & -0.0489 & 0.0396 & 6 \\
\hline 0 & -3 & 0.0933 & 0.358 & 0.110 & 7 \\
\hline 0 & -3 & 0.0978 & 0.362 & 0.105 & 8 \\
\hline 0 & 3 & 0.0118 & -0.0801 & 0.00685 & 9 \\
\hline 0 & 3 & 0.0397 & -0.0548 & 0.0357 & 10 \\
\hline 0 & -4 & -0.101 & 0.272 & -0.0831 & 41 \\
\hline 0 & $\begin{array}{l}-4 \\
-4\end{array}$ & -0.0969 & 0.276 & -0.0797 & 42 \\
\hline 0 & 4 & 0.00765 & -0.084 & 0.00477 & 43 \\
\hline 0 & $\begin{array}{l}4 \\
4\end{array}$ & 0.0048 & -0.0865 & 0.00243 & 44 \\
\hline 0 & -5 & -0.0747 & 0.387 & -0.0573 & $I I$ \\
\hline 0 & -5 & -0.102 & 0.362 & -0.0826 & 45 \\
\hline 0 & 5 & 0.0115 & -0.0805 & 0.00899 & 46 \\
\hline 0 & 5 & -0.0161 & -0.106 & -0.0180 & \\
\hline-1 & 0 & -0.048 & -0.135 & -0.0544 & \\
\hline-1 & 0 & 0.148 & 0.0434 & 0.139 & \\
\hline-1 & -1 & 0.0839 & 0.0763 & 0.0833 & \\
\hline-1 & 1 & -0.0845 & -0.259 & -0.0963 & \\
\hline-1 & 1 & 0.0894 & -0.100 & 0.0781 & \\
\hline-1 & -2 & -0.0791 & 0.019 & -0.0711 & \\
\hline-1 & 2 & 0.0185 & -0.12 & 0.0136 & \\
\hline-1 & 2 & 0.0314 & -0.108 & 0.0234 & \\
\hline-1 & -3 & -0.0208 & 0.163 & -0.0129 & \\
\hline-1 & 3 & 0.0318 & -0.0923 & 0.0274 & \\
\hline-1 & 3 & 0.0542 & -0.072 & 0.0498 & \\
\hline-1 & -4 & -0.089 & 0.192 & -0.076 & \\
\hline-1 & 4 & 0.0147 & -0.100 & 0.0107 & \\
\hline-1 & 4 & 0.0102 & -0.104 & 0.00784 & \\
\hline-1 & -5 & -0.0307 & 0.336 & -0.0172 & \\
\hline-1 & 5 & -0.0145 & -0.122 & -0.0163 & \\
\hline-1 & 5 & -0.034 & -0.14 & -0.0356 & \\
\hline-1 & 6 & -0.0186 & -0.123 & -0.021 & \\
\hline-1 & 7 & -0.00311 & -0.107 & -0.005 & \\
\hline-1 & 8 & 0.0204 & -0.0837 & 0.0191 & \\
\hline-1 & 9 & -0.0105 & -0.111 & -0.0112 & \\
\hline-1 & 10 & 0.00582 & -0.0947 & 0.00479 & \\
\hline 1 & 0 & 0.154 & 0.231 & 0.16 & \\
\hline
\end{tabular}


TABLE A -2

TRUE VARIANCE $=1$.

\begin{tabular}{|c|c|c|c|c|c|}
\hline $\begin{array}{l}\text { Estimated } \\
\text { Mean }\end{array}$ & $\begin{array}{l}\text { True } \\
\text { Mean }\end{array}$ & $\begin{array}{l}\text { MLE } \\
\text { Relative Error }\end{array}$ & $\begin{array}{c}\text { Bayes } \\
\text { Relative Error }\end{array}$ & $\begin{array}{l}\text { Modified Bayes } \\
\text { Relative Error }\end{array}$ & $\begin{array}{c}\text { Reference } \\
\text { No. }\end{array}$ \\
\hline 0 & 0 & 0.489 & 0.444 & 0.485 & 35 \\
\hline 0 & -1 & -0.494 & -0.358 & -0.482 & 36 \\
\hline 0 & 1 & 0.373 & 0.248 & 0.362 & 37 \\
\hline 0 & -2 & -0.41 & -0.19 & -0.391 & 38 \\
\hline 0 & 2 & -0.121 & -0.201 & -0.128 & 12 \\
\hline 0 & -3 & 0.0748 & 0.341 & 0.0964 & 13 \\
\hline 0 & 3 & 0.114 & 0.0127 & 0.107 & 39 \\
\hline 0 & -4 & -0.0408 & 0.327 & -0.0108 & 14 \\
\hline 0 & 4 & -0.0684 & -0.153 & -0.0752 & 15 \\
\hline 0 & -5 & 0.0436 & 0.494 & 0.0813 & 16 \\
\hline 0 & 5 & -0.0378 & -0.125 & -0.0443 & 17 \\
\hline-1 & 0 & -0.372 & -0.429 & -0.377 & 18 \\
\hline-1 & -1 & -0.105 & -0.0953 & -0.104 & 40 \\
\hline-1 & 1 & 0.612 & 0.375 & 0.594 & \\
\hline-1 & -2 & -0.220 & -0.11 & -0.210 & \\
\hline-1 & 2 & -0.252 & -0.365 & -0.261 & 19 \\
\hline-1 & -3 & -0.336 & -0.124 & -0.318 & \\
\hline-1 & 3 & -0.106 & -0.218 & -0.115 & 20 \\
\hline-1 & -4 & -0.0517 & 0.226 & -0.0295 & 47 \\
\hline-1 & 4 & 0.0164 & -0.0988 & 0.00732 & \\
\hline-1 & -5 & -0.167 & 0.211 & -0.141 & \\
\hline $\begin{array}{l}-1 \\
-1\end{array}$ & 5 & 0.030 & -0.0818 & 0.0213 & 48 \\
\hline $\begin{array}{r}-1 \\
1\end{array}$ & 0 & 0.317 & 0.379 & 0.323 & $\mp 0$ \\
\hline 1 & -1 & -0.166 & 0.0311 & -0.148 & \\
\hline 1 & 1 & -0.299 & -0.271 & -0.296 & \\
\hline 1 & -2 & 0.119 & 0.381 & 0.141 & \\
\hline I & 2 & 0.0429 & -0.00646 & 0.0385 & \\
\hline 1 & -3 & 0.303 & 0.639 & 0.33 & \\
\hline 1 & 3 & -0.177 & -0.221 & -0.181 & \\
\hline 1 & -4 & -0.0177 & 0.443 & 0.0216 & \\
\hline 1 & 4 & 0.0136 & -0.0558 & 0.00769 & \\
\hline 1 & -5 & -0.228 & 0.338 & -0.192 & \\
\hline 1 & 5 & 0.0678 & -0.0111 & 0.0618 & \\
\hline-2 & 0 & 0.156 & -0.0399 & 0.139 & \\
\hline-2 & -1 & -0.377 & -0.433 & -0.382 & \\
\hline-2 & 1 & 0.140 & -0.145 & 0.116 & \\
\hline-2 & -2 & -0.0923 & -0.084 & -0.0916 & \\
\hline-2 & 2 & 0.0124 & -0.171 & -0.00241 & \\
\hline-2 & -3 & 0.192 & 0.265 & 0.199 & \\
\hline-2 & 3 & -0.0303 & -0.179 & -0.0417 & \\
\hline-2 & -4 & 0.276 & 0.433 & 0.290 & \\
\hline-2 & 4 & -0.0516 & -0.183 & -0.0623 & \\
\hline$-\overline{2}$ & -5 & 0.361 & 0.601 & 0.381 & \\
\hline-2 & 5 & -0.0041 & -0.131 & -0.0115 & \\
\hline 2 & 0 & 0.0452 & 0.223 & 0.061 & \\
\hline 2 & -1 & 0.0623 & 0.329 & 0.0856 & \\
\hline
\end{tabular}


TABLE A-3

TRUE VARIANCE $=10$

\begin{tabular}{|c|c|c|c|c|c|}
\hline $\begin{array}{c}\text { Estimated } \\
\text { Mean }\end{array}$ & $\begin{array}{l}\text { True } \\
\text { Mean }\end{array}$ & $\begin{array}{c}\text { MLE } \\
\text { Relative Error }\end{array}$ & $\begin{array}{c}\text { Bayes } \\
\text { Relative Error }\end{array}$ & $\begin{array}{l}\text { Modified Bayes } \\
\text { Relative Error }\end{array}$ & $\begin{array}{l}\text { Reference } \\
\text { No. }\end{array}$ \\
\hline $\begin{array}{l}0 \\
0 \\
0 \\
0 \\
0 \\
0 \\
0 \\
0 \\
0 \\
0 \\
0 \\
-1 \\
-1 \\
-1 \\
-1 \\
-1 \\
-1 \\
-1 \\
-1 \\
-1 \\
-1 \\
-1 \\
1 \\
1 \\
1 \\
1 \\
1 \\
1 \\
1 \\
1 \\
1 \\
1 \\
1 \\
-2 \\
-2 \\
-2 \\
-2 \\
-2 \\
-2 \\
-2 \\
-2 \\
-2 \\
-2 \\
-2 \\
\end{array}$ & $\begin{array}{r}0 \\
-1 \\
1 \\
-2 \\
2 \\
-3 \\
3 \\
-4 \\
4 \\
-5 \\
5 \\
0 \\
-1 \\
1 \\
-2 \\
2 \\
-3 \\
3 \\
-4 \\
4 \\
-5 \\
5 \\
0 \\
-1 \\
1 \\
-2 \\
2 \\
-3 \\
3 \\
-4 \\
4 \\
-5 \\
5 \\
0 \\
-1 \\
1 \\
-2 \\
2 \\
-3 \\
3 \\
-4 \\
4 \\
-5 \\
5 \\
\end{array}$ & $\begin{array}{c}1.17 \\
-1.15 \\
0.167 \\
-0.253 \\
-0.573 \\
-1.25 \\
0.0229 \\
-1.3 \\
0.321 \\
-0.084 \\
0.184 \\
1.45 \\
1.50 \\
-1.13 \\
1.45 \\
0.0417 \\
0.138 \\
-0.199 \\
0.721 \\
-0.478 \\
0.0390 \\
0.114 \\
0.938 \\
-1.06 \\
-0.692 \\
0.153 \\
-0.371 \\
-0.895 \\
0.263 \\
0.370 \\
-0.131 \\
-2.84 \\
-0.0515 \\
-0.361 \\
0.009 \\
0.222 \\
0.90 \\
0.08 \\
-0.722 \\
-0.064 \\
-0.771 \\
0.256 \\
+0.821 \\
0.195 \\
-1\end{array}$ & $\begin{array}{l}1.06 \\
-0.956 \\
0.0613 \\
-0.0477 \\
-0.612 \\
-0.864 \\
-0.0701 \\
-0.818 \\
0.201 \\
0.378 \\
0.0761 \\
1.22 \\
1.37 \\
-1.21 \\
1.41 \\
-0.0984 \\
0.307 \\
-0.303 \\
0.928 \\
-0.548 \\
0.399 \\
-0.00587 \\
0.944 \\
-0.784 \\
-0.629 \\
0.412 \\
-0.383 \\
-0.405 \\
0.179 \\
0.791 \\
-0.187 \\
-2.04 \\
-0.120 \\
-0.310 \\
-0.0823 \\
-0.0711 \\
0.826 \\
-0.103 \\
-0.565 \\
-0.210 \\
-0.519 \\
0.0960 \\
-0.473 \\
0.0496\end{array}$ & 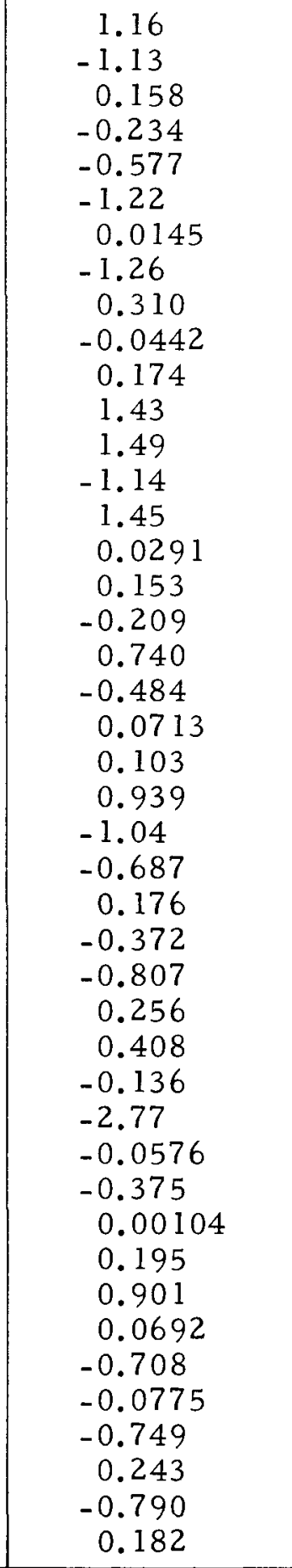 & $\begin{array}{l}24 \\
25 \\
26 \\
27 \\
28 \\
29 \\
30 \\
49\end{array}$ \\
\hline
\end{tabular}

LMEC -69-8 
The first observation is 4.2142. Thus, the maximum likelihood estimate for the mean is

$$
\hat{\mu}(\mathrm{mle})=\overline{\mathrm{x}}=\frac{4.2142}{1}=4.2142
$$

With $\mathrm{n}=\mathrm{n}_{\mathrm{o}}=1$, the Bayes estimate for the mean is

$$
\begin{aligned}
\hat{\mu}(\text { Bayes }) & =\frac{n \bar{x}+n_{0} \hat{\mu}(\text { prior })}{n+n_{o}} \\
& =\frac{4.2142+0 .}{2}=2.1071 .
\end{aligned}
$$

At the first observation, the modified Bayes estimate for the mean cannot actually be computed, since the variance estimates have no meaning. After the second observation, 4.9135, a new maximum likelihood estimate may be computed for the mean, viz.,

$$
\hat{\mu}(\mathrm{mle})=\bar{x}=\frac{4.2142+4.9135}{2}=4.5638
$$

The Bayes estimate now uses $n_{0}=1$ and $n=2$, to obtain

$$
\begin{aligned}
\hat{\mu}(\text { Bayes }) & =\frac{2 \bar{x}+\hat{\mu}(\text { prior })}{2+1} \\
& =\frac{4.2142+4.9135+0}{3}=3.0425 .
\end{aligned}
$$

Thus, on the basis of $\hat{\mu}($ mle $)$,

$$
\hat{\sigma}^{2}(\mathrm{mle})=\frac{\sum_{1}^{2}(\mathrm{x}-\overline{\mathrm{x}})^{2}}{2-1} \frac{2(0.3496)^{2}}{1}=0.24446
$$


and on the basis of $\hat{\mu}$ (Bayes),

$$
\hat{\sigma}^{2}(\text { Bayes })=\frac{\sum_{1}^{2}[x-\hat{\mu}(\text { Bayes })]^{2}}{2+1-1}=\frac{2(1.8710)^{2}}{2}=4.8731 .
$$

Then $\xi$ is the ratio,

$$
\xi=\frac{\hat{\sigma}^{2}(\text { mle })}{\hat{\sigma}^{2}(\text { Bayes })}=\frac{0.24446}{4.8731}=0.050166
$$

which makes it possible to find the modified Bayes estimate for the mean,

$$
\begin{aligned}
\hat{\mu}(\bmod . \text { Bayes }) & =\frac{4.2142+4.9135+(0.050166)(0.30425)}{2+0.050166} \\
& =4.5266 .
\end{aligned}
$$

The program thus continues until 10 measurements have been made. The final estimates are

$$
\begin{gathered}
\hat{\mu}(\text { mle })=4.8107 \\
\hat{\mu}(\text { Bayes })=4.3734 \\
\hat{\mu}(\text { mod. Bayes })=4.7785 .
\end{gathered}
$$

To compute the relative error for each estimate, the program picks out the true mean which has been input to the normal random number generator, yielding

$$
\begin{aligned}
& \epsilon_{\mathrm{Rel}}(\mathrm{mle})=\frac{4.8107-5 \cdot}{5 \cdot}=-0.037846 \cong-0.0378 \\
& \epsilon_{\operatorname{Rel}}(\text { Bayes })=\frac{4.3734-5 .}{5 .}=-0.12531 \cong-0.125
\end{aligned}
$$




$$
\epsilon_{\operatorname{Rel}}(\bmod . \text { Bayes })=\frac{4.7785-5}{5 .}=-0.044299 \cong-0.0443
$$

In this way, it is possible to perform an almost unlimited number of tests for an estimation procedure. With more time available, it is likely that significant improvements could be made in the modified Bayes estimation procedure by studying the statistical behavior of its error.

More than 500 simulation runs of this type were conducted; thus, only an abbreviated summary is given here. Each of the previous three listings (Tables A-1 through A-3) has a different true variance value and provides some arbitrarily selected results for the relative errors. The reference numbers will serve to point out some properties of the results as they are discussed in the subsequent analysis and conclusions.

\section{Analysis and Conclusions}

It is worthwhile to make the following observations:

1) The modified Bayes estimate tends to be less biased (has smaller absolute relative error) than the standard Bayes estimate. This is displayed by Reference Numbers 1 through 30. For example, Reference No. 17 (Table A-2) has

$$
\begin{gathered}
\epsilon_{\mathrm{Rel}}(\mathrm{mle})=-0.0378 \\
\epsilon_{\mathrm{Rel}}(\text { Bayes })=-0.125 \\
\epsilon_{\mathrm{Rel}}(\bmod . \text { Bayes })=-0.0443 \\
|-0.0443|<|-0.125| .
\end{gathered}
$$

and

2) When the modified Bayes estimate has more bias than the standard Bayes estimate, that bias is usually not excessive and compares 
favorably with the bias of the maximum likelihood estimate. Examples of this are Reference Numbers 31 through 40. Consider Reference No. 31; here,

$$
\begin{gathered}
\epsilon_{\mathrm{Rel}}(\mathrm{mle})=-0.266 \\
\epsilon_{\mathrm{Rel}}(\text { Bayes })=-0.242 \\
\epsilon_{\mathrm{Rel}}(\bmod . \text { Bayes })=-0.264
\end{gathered}
$$

and note that

$$
|0.266|-|0.264|=0.002
$$

3) When the relative error of the maximum likelihood estimate is of a different sign than the relative error of the Bayes estimate, the modified Bayes estimate is usually quite good. This property is exhibited by Reference Numbers 1, 3, 5, 6, 9, and 41 through 50 . For instance, Reference No. 50 obtains

$$
\begin{gathered}
\epsilon_{\mathrm{Rel}}(\mathrm{mle})=0.00937 \\
\epsilon_{\mathrm{Rel}}(\text { Bayes })=-0.0823, \text { and } \\
\epsilon_{\mathrm{Rel}}(\bmod . \text { Bayes })=0.00104
\end{gathered}
$$

While Bayesian point estimation is not the major preoccupation here, it is certainly a logical prelude to the Bayesian estimation of curves and assists in drawing the following conclusions:

1) The estimation procedure to be developed for general classes of data should not be restricted to a fixed type of random variable; but, rather, should be adaptable to several kinds of probability density functions. 
2) The risk due to bias entailed by a standard Bayes estimation procedure can be mitigated by making appropriate modifications.

3) There exists a need for further development of the concept of a weighted prior estimate, in addition to the concept of an information-gain function. 


\section{APPENDIX B}

\section{AN EXAMPLE OF BAYESIAN FITTING OF POLYNOMIAL REGRESSION CURVES}

Comparison of the Prior Estimate With the Least Squares Estimate

The object of this procedure is to fit prior and experimental data to a polynomial function. The combination of these two kinds of information is accomplished by means of a statistical method designed to estimate and ultimately minimize the composite error, while at the same time providing a weighting coefficient for the prior estimate.

Before experimentation, a prior estimate of the regression curve is obtained. This estimate is of the form,

$$
\mathrm{y}_{\mathrm{P}}=\sum_{i=0}^{\mathrm{k}} \mathrm{c}_{i} \mathrm{x}^{\mathrm{i}}+\mathrm{R}_{\mathrm{P}}
$$

where $R_{P}$ is a residual term, indicating the error, which can be evaluated after at least $k+2$ observations. Note that a nonzero residual error almost always occurs when the number of polynomial coefficients is exceeded by the number of data points. After at least $m+2$ observations have been made, $a$ least-squares fit may be made to the data points, where the estimate is of the form,

$$
\mathrm{y}_{\mathrm{LS}}=\sum_{i=0}^{\mathrm{m}} \mathrm{d}_{i} \mathrm{x}^{i}+\mathrm{R}_{\mathrm{LS}}
$$

and $R_{L S}$ is the residual error.

The revised estimate will be of the form,

$$
\widehat{y}=b y_{p}+(1-b) y_{L S}=\sum_{i=0}^{r} e_{i} x^{i}+\widehat{R} \text {, }
$$

where $b$ is a number that indicates the extent to which the prior estimate represents the true $y$. 
The value of $b$ is defined as a probability, given by

$$
b=\operatorname{Prob}\left(R_{p} \text { has the same distribution as } R_{L S}\right)
$$

Thus, after at least $m+2$ or $k+2$ (whichever is greater) observations, probability density functions for both $R_{p}$ and $R_{L S}$ may be approximated as depicted in the following sketches:
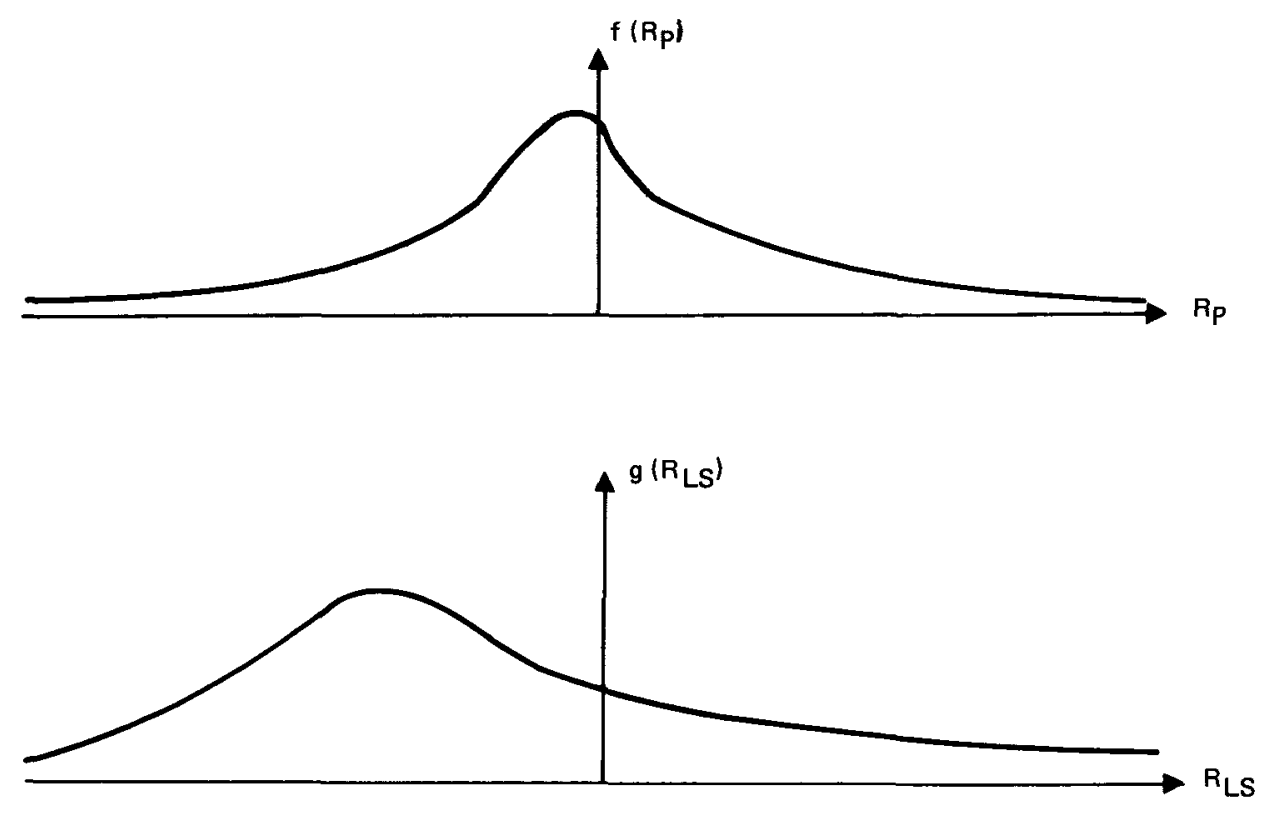

These density functions can be superimposed as indicated in the following sketch:

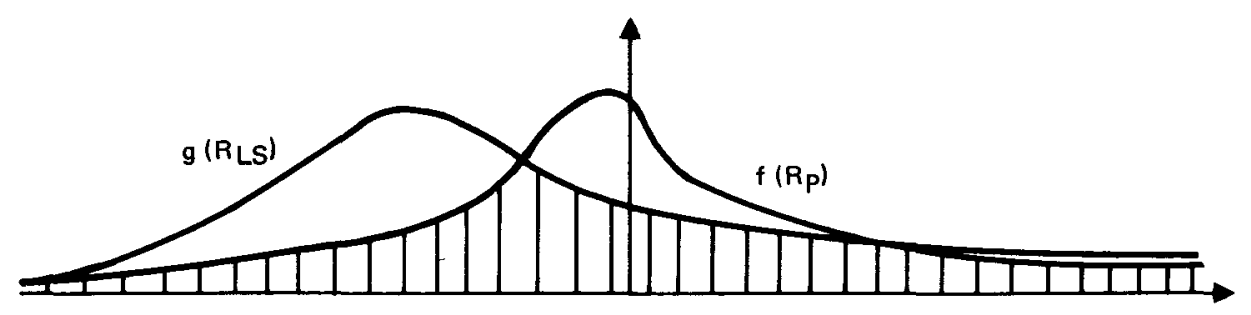

The shaded region of overlap then has area equal to $b$. 


$$
b=\int_{-\infty}^{\infty}\{f(y) U[g(y)-f(y)]+g(y) U[f(y)-g(y)]\} d y,
$$

where $U$ is the unit step function.

Now $\hat{y}=b y_{p}+(1-b) y_{L S}$ has a probability density, $h$, associated with its residual error. To cover a wide range of random variables, all three density functions are assumed to be Weibull; i.e.,

$$
\begin{aligned}
& f(y)=\frac{\beta_{1}\left(y-\gamma_{1}\right)^{\beta_{1}-1} \exp -\left[\left(y-\gamma_{1}\right)^{\beta_{1} / \alpha_{1}}\right]}{\alpha_{1}} \\
& g(y)=\frac{\beta_{2}\left(y-\gamma_{2}\right)^{\beta_{2}-1} \exp -\left[\left(y-\gamma_{2}\right)^{\beta_{2} / \alpha_{2}}\right]}{\alpha_{2}} \\
& h(y)=\frac{\beta_{3}\left(y-\gamma_{3}\right)^{\beta_{3}-1} \exp -\left[\left(y-\gamma_{3}\right)^{\beta_{3} / \alpha_{3}}\right]}{\alpha_{3}}
\end{aligned}
$$

Selection of the next measurement to be made is performed by choosing $\mathrm{x}$ so as to minimize the function,

$$
v(x)=\sum_{j=1}^{n}\left(y_{j}-\sum_{i=0}^{r} e_{i} x^{i}\right)^{2}
$$


where

$$
\begin{aligned}
\widehat{y} & =b y_{p}+(1-b) y_{L S} \\
& =b\left(\sum_{i=0}^{k} c_{i} x^{i}+R_{p}\right)+(1-b)\left(\sum_{i=0}^{m} d_{i} x^{i}+R_{L S}\right) \\
& =\sum_{i=0}^{r} e_{i} x^{i}+\widehat{R} \text {, and } \\
r & =\max (k, m) .
\end{aligned}
$$

In this example, information-gain is associated with a decrease in $v(x)$ and it is tacitly assumed that all measurements entail equal cost, so that maximum utility is realized when the greatest decrease in $\mathrm{v}(\mathrm{x})$ occurs. The stopping rule arises from an estimate of the probability that the true $y$ deviates from the computed $\widehat{y}$ by more than a prespecified tolerable error.

Implementation of the Method

By successive approximations, calculations are made and for the Weibull density,

$$
f(y)=\alpha \lambda y^{\alpha-1} \exp \left(-\lambda y^{\alpha}\right)
$$

where y may correspond to $y_{L S}$ or $y_{p}$. Based on this density, a mean and a variance for $y_{L S}$ are obtained as follows:

$$
\begin{gathered}
\mu_{L S}=\Gamma\left(\frac{1}{\alpha}+1\right) \lambda^{-1 / \alpha} \\
\sigma_{L S}{ }^{2}=\lambda^{-2 / \alpha}\left\{\Gamma\left(\frac{2}{\alpha}+1\right)-\left[\Gamma\left(\frac{1}{\alpha}+1\right)\right]^{2}\right\}
\end{gathered}
$$

Rather than to explicitly calculate the value of $b$, as defined above, $b$ is approximated by estimating the probability that $\mu_{L S} \pm 3 \sigma_{L S}$ satisfies the Weibull density for $\mathrm{y}_{\mathrm{P}}$. This estimate is performed by approximating the shaded area depicted below, defining $f\left(y_{P}\right)$ as the two-parameter Weibull density for the prior estimate.

$$
\text { LMEC-69-8 }
$$




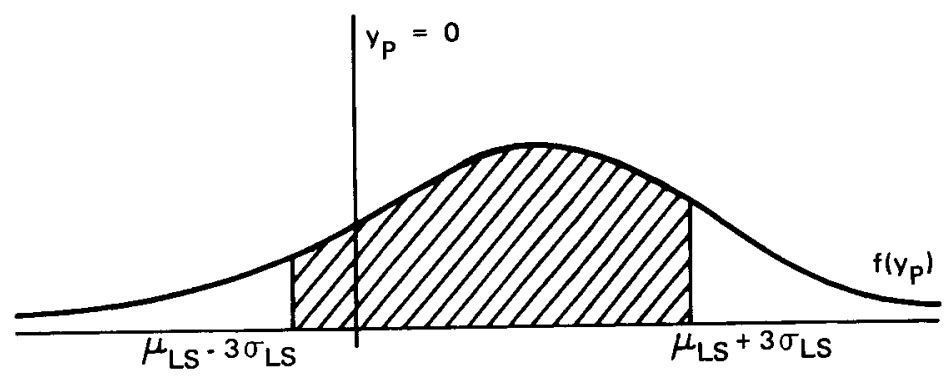

This area is then obtained by a two-point Gauss quadrature formula. The next $\mathrm{x}$ is chosen to minimize the function,

$$
v(x)=\sum_{i=1}^{n}\left(\hat{y}_{i}-e_{o}-e_{i} x\right)^{2}
$$

so that

$$
x=\frac{1}{e_{1}}\left(\frac{\sum_{i=1}^{n} y_{i}}{n}-e_{o}\right)
$$

Figures B-1 and B-2 contain rudimentary flow diagrams of the process.

\section{A Computational Example}

Next the use of this algorithm is demonstrated with actual experimental data. Two variables are involved, $H$ and $W . H$ is the square of the ratio of the Brinnel hardness values of two metals and $W$ is a measure of the wear which results from their sliding contact.

Theory ${ }^{*}$ predicts a linear relationship between $\mathrm{H}$ and $\mathrm{W}$, which may be represented as $\mathrm{W}=\mathrm{a}+\mathrm{bH}$; by scanning some past results, the arbitrary prior estimate of the coefficients has been selected as $\mathrm{C}_{0}=3$ and $\mathrm{C}_{1}=2 / 3$, viz.,

$$
\mathrm{W}_{\mathrm{p}}=3+(2 / 3) \mathrm{H}
$$

*E. Rabinowicz, Friction and Wear of Materials, (John Wiley and Sons, New York, N.Y., 1965) 


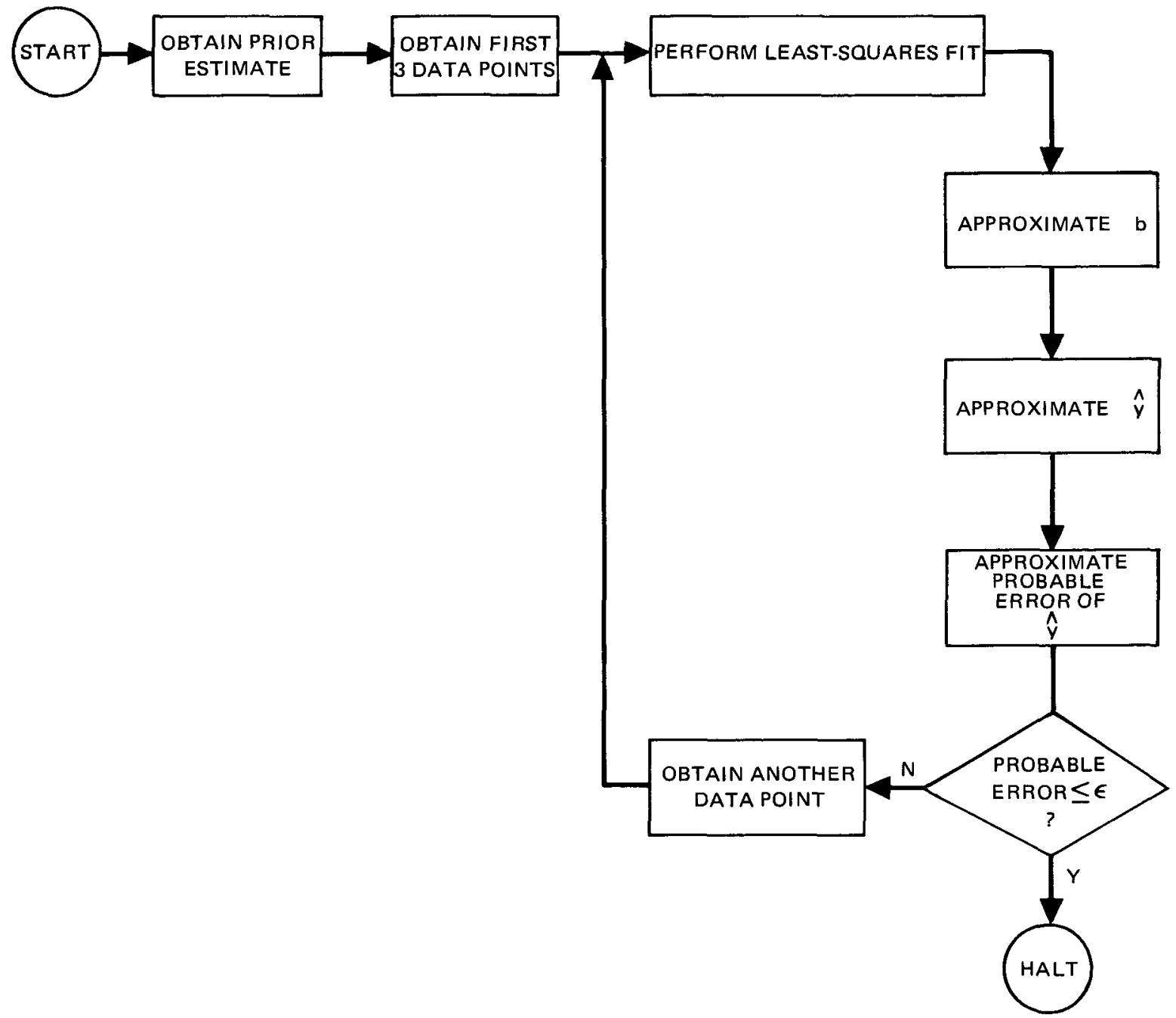

Figure B-1. Measurement Sequencing Algorithm

LMEC-69-8 


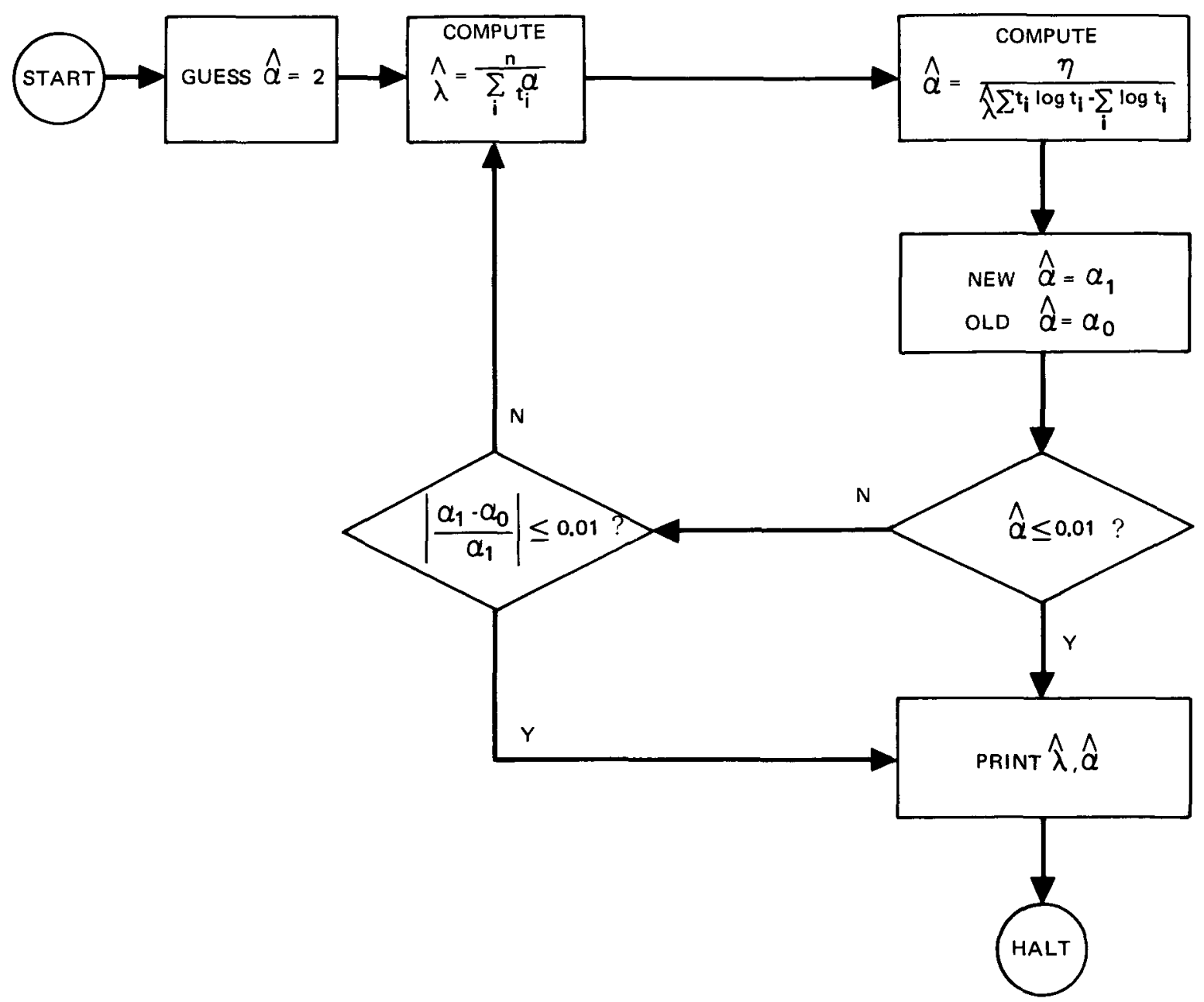

Figure B-2. Algorithm to Compute Weibull Coefficients

LMEC-69-8 


\section{Program to Calculate b}

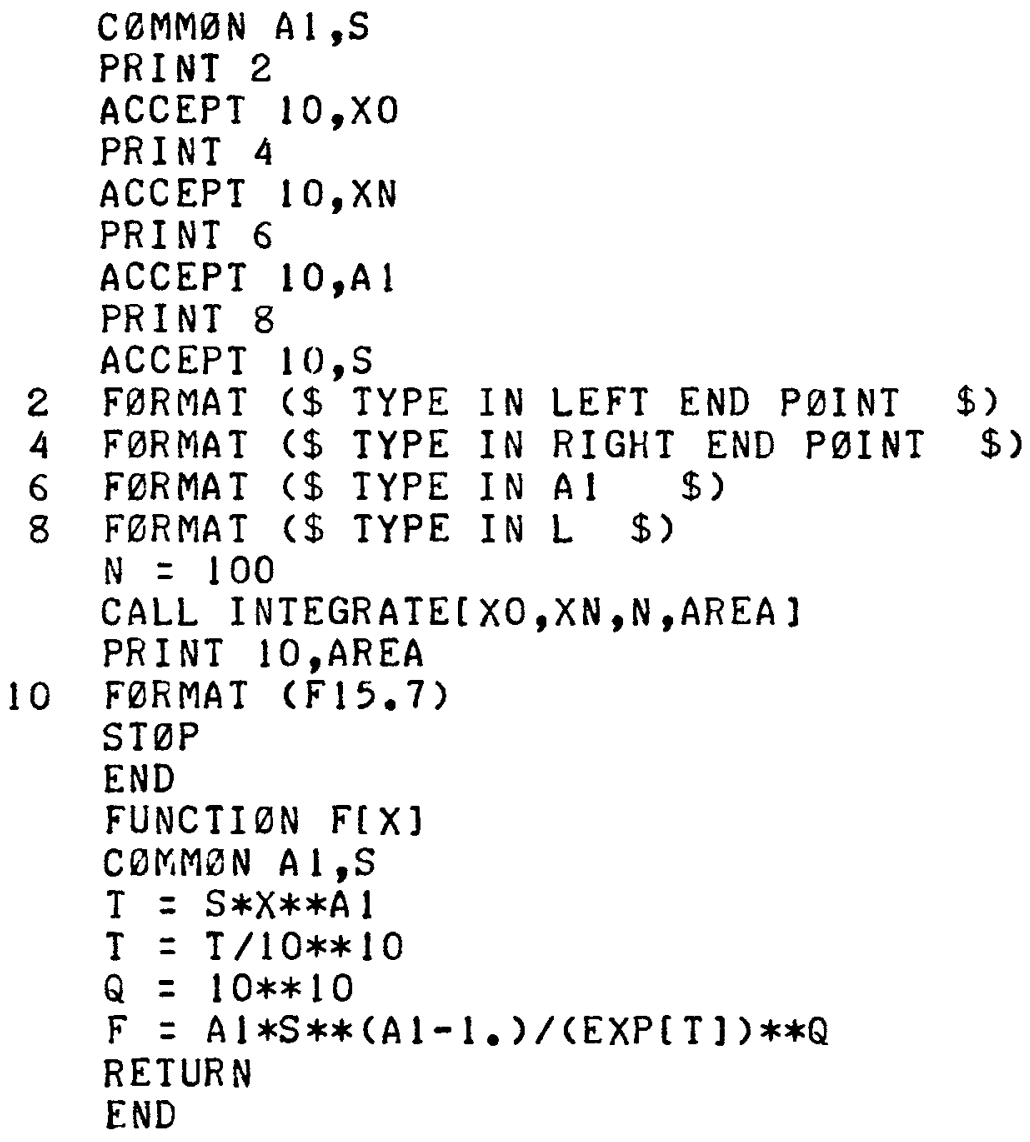




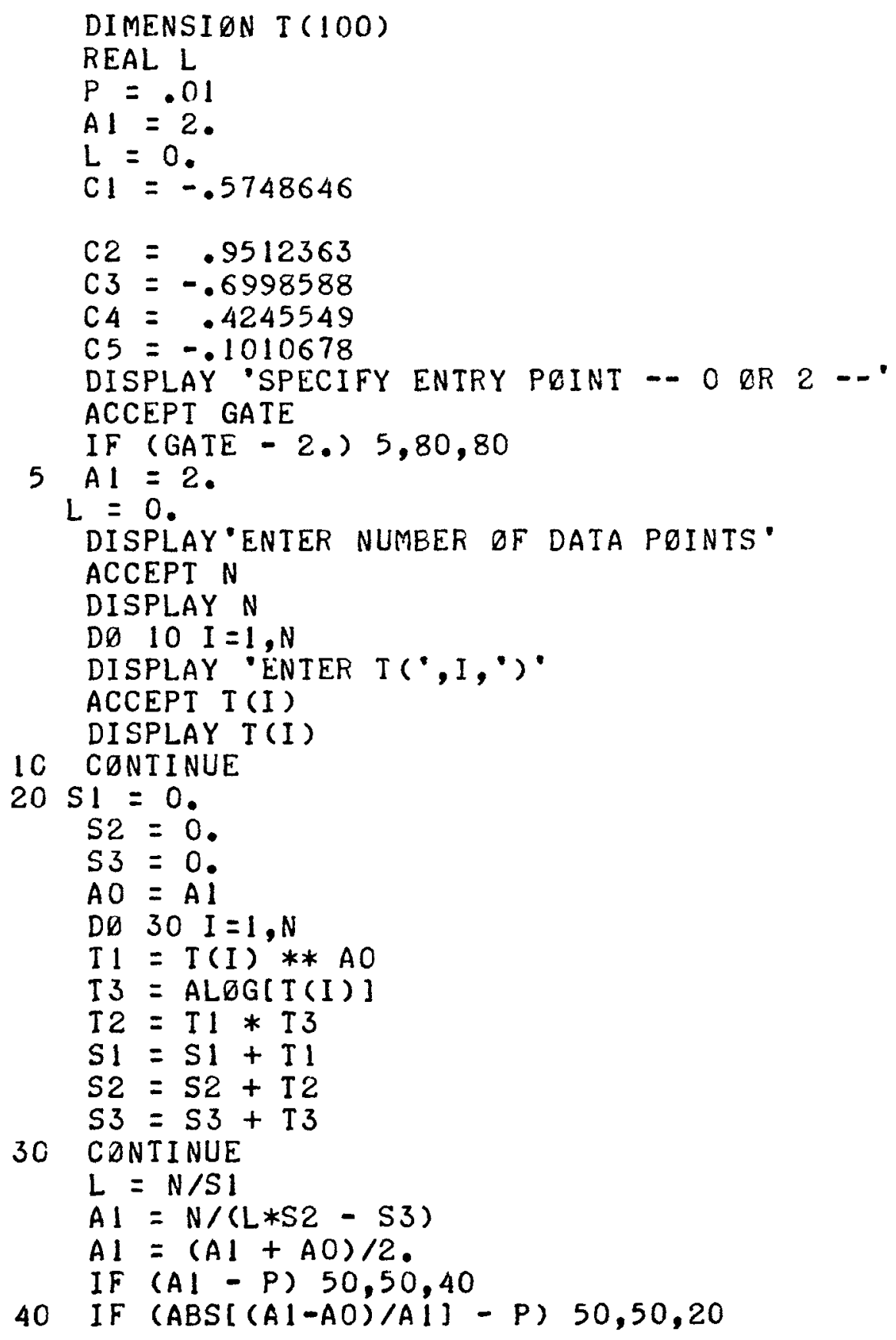




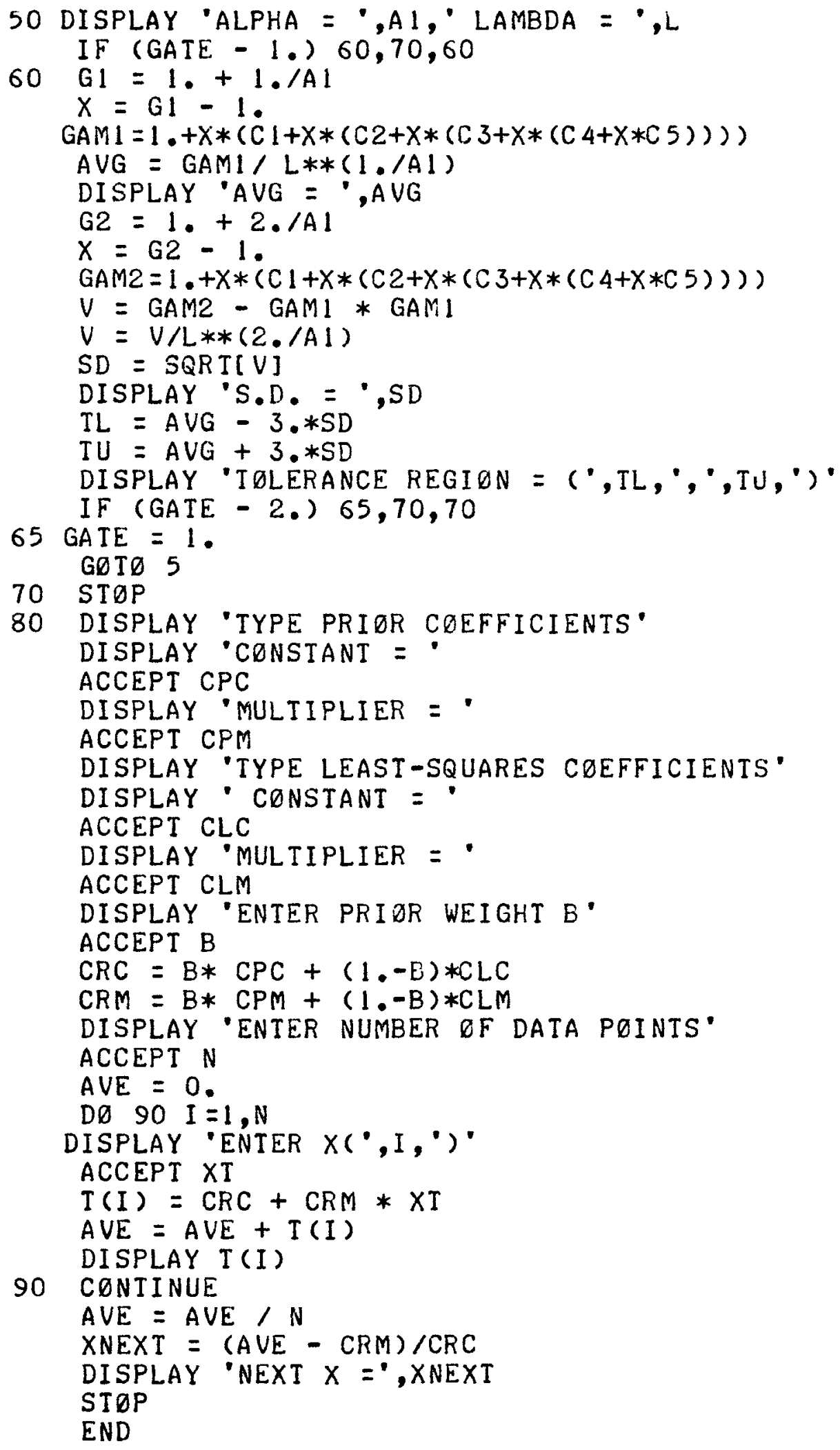

END 
Beginning with three data points, the prior estimate, $W_{p}$ ' is compared with the least-squares (linear) estimate, $W_{L_{S}}$, and an additional measurement is then selected to be incorporated in the next stage. The process thus continues in a stepwise fashion until the RMS error has been decreased to a tole rable level. Because of time constraints, only nine data points have been used in this example.

\section{Computer Programs}

FORTRAN programs used in this example are listed on the following pages.

\section{Results}

Figures B-3 through B-9 demonstrate the use of this method for weighting the prior estimate and selecting the next value of $H$ to be used. The reader may observe how the prior estimate receives progressively less weight as more test data are incorporated.

An interesting observation is that sampling is indeed increased where there is less certainty (or more variation) in the experimental data.

Analysis and Conclusions

The progressive and rapid decrease of the values of $b$ is noteworthy. As may be anticipated, this is caused by the fact that the distribution of errors with respect to the prior estimate does not resemble the distribution of errors with respect to the least-squares linear fit. This disparity is caused by at least two conditions:

1) The prior estimate is not very close to the least-squares fit which appears to be developing from these data

2) The experimental data show considerable "scatter" and are thus difficult to identify in the first place.

This example may be compared with a hypothetical (more optimal) case. If it is assumed that the experimental results exhibited less variability and that the prior estimates were closer to the true data, then it is apparent that the distribution for $R_{P}$ would be very similar to the distribution for $R_{L S}$. In that case, b would assume very large values - perhaps 90 to $95 \%$. 


$$
\begin{array}{ll}
H_{1}=1.00 & W_{1}=10.31 \\
H_{2}=4.89 & W_{2}=4.93 \\
H_{3}=0.313 & W_{3}=3.55
\end{array}
$$

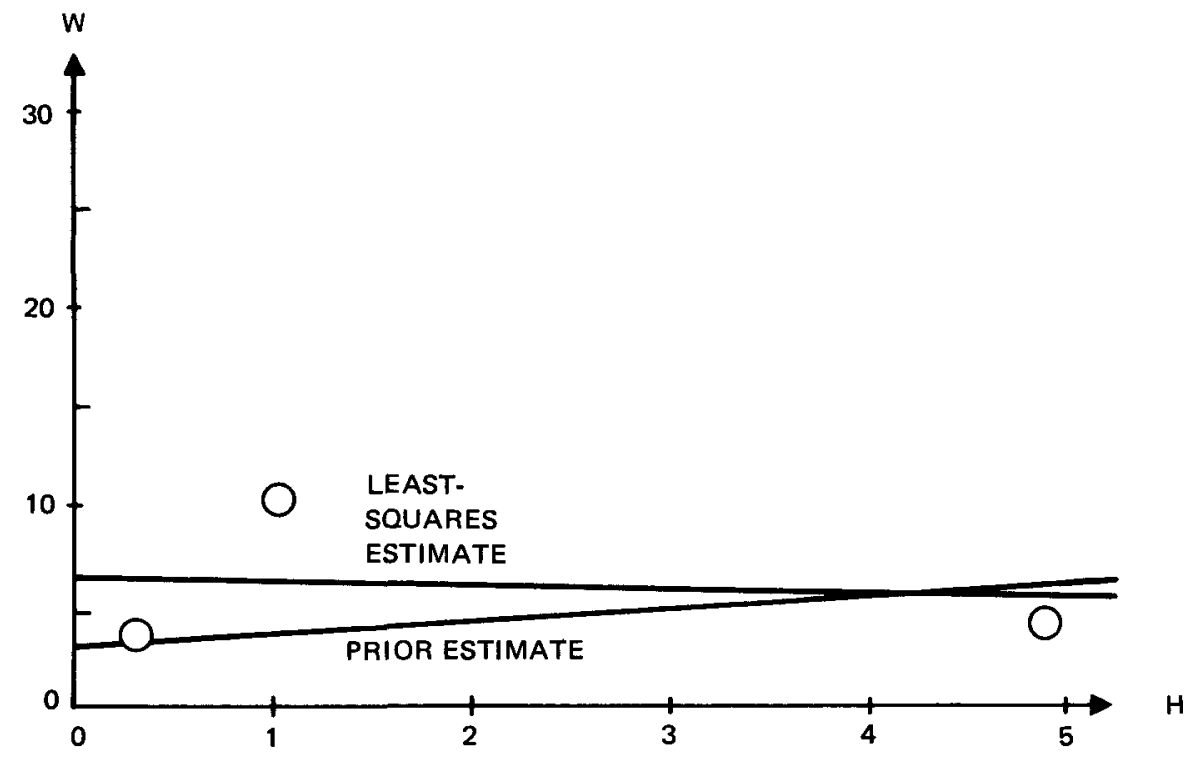

$$
\text { LEAST-SQUARES: } \quad \begin{aligned}
r & =\text { CORRELATION COEFFICIENT }=-0.18844 \\
d_{0} & =6.8272 \\
d_{1} & =-0.2727
\end{aligned}
$$

PRIOR COMPARISON: $\quad b=0.354$

$$
H_{4}=1.011
$$

NEXT STEP:

("NEXT X", DISPLAYED BY

PROGRAM, FOLLOWING STATEMENT 90)

BY REASON OF DATA LIMITATIONS, CHOOSE $H_{4}=1.00$

Figure B-3. First Stage (3 points) 


$$
\begin{array}{ll}
\mathrm{H}_{1}=1.00 & \mathrm{~W}_{1}=10.31 \\
\mathrm{H}_{2}=4.89 & \mathrm{~W}_{2}=4.93 \\
\mathrm{H}_{3}=0.313 & \mathrm{~W}_{3}=3.55 \\
\mathrm{H}_{4}=1.00 & \mathrm{~W}_{4}=32.5
\end{array}
$$

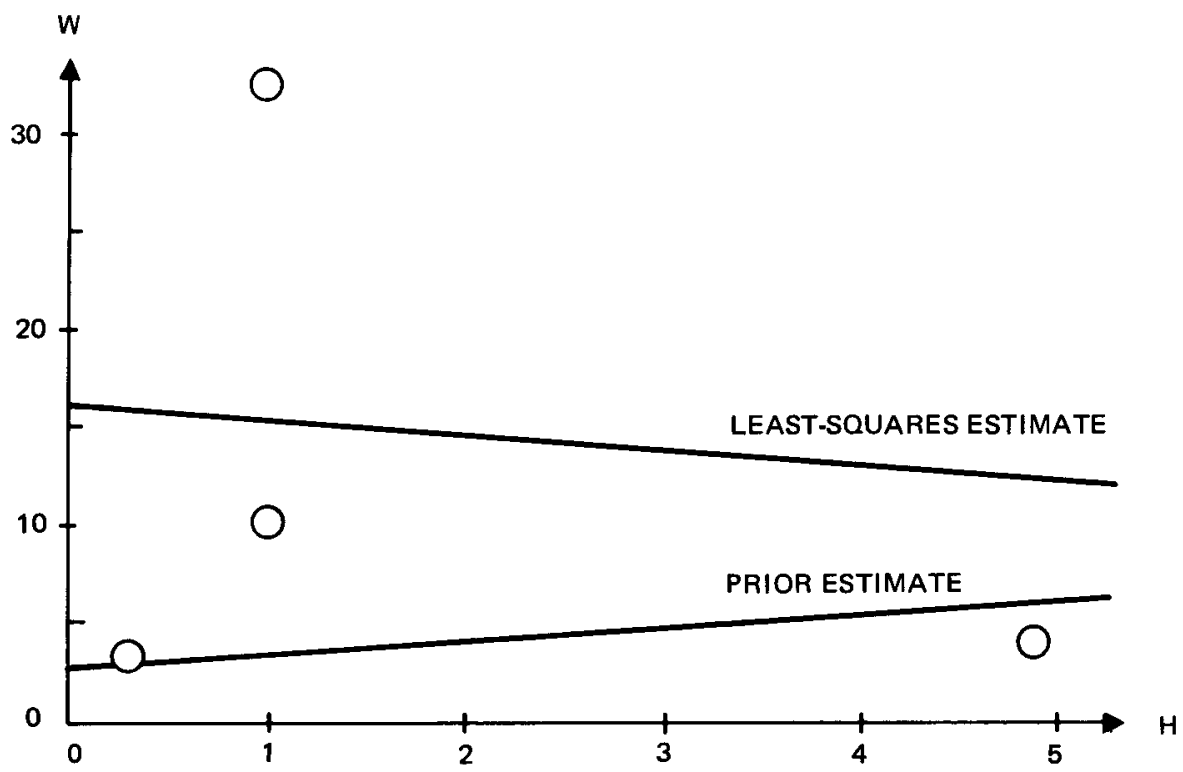

$$
\begin{aligned}
& \text { LEAST-SQUARES: } \quad r=\mathbf{0 . 2 8 9 5} \\
& d_{0}=16.1827 \\
& d_{1}=.1 .8660 \\
& \text { PRIOR COMPARISON: } \quad b=0.000039 \\
& \text { NEXT STEP: } \quad H_{5}=0.908
\end{aligned}
$$

NOTE THAT THE PRIOR WEIGHTING COEFFICIENT b HAS DECREASED BY ABOUT $10^{-4}$ AND THAT $H_{5}$ IS CHOSEN IN A REGION OF

Figure B-4. Second Stage (4 points)

LMEC -69-8 


$\begin{array}{ll}H_{1}=1.00 & W_{1}=10.31 \\ H_{2}=4.89 & W_{2}=4.93 \\ H_{3}=0.313 & W_{3}=3.55 \\ H_{4}=1.00 & W_{4}=32.5 \\ H_{5}=1.00 & W_{5}=7.95\end{array}$
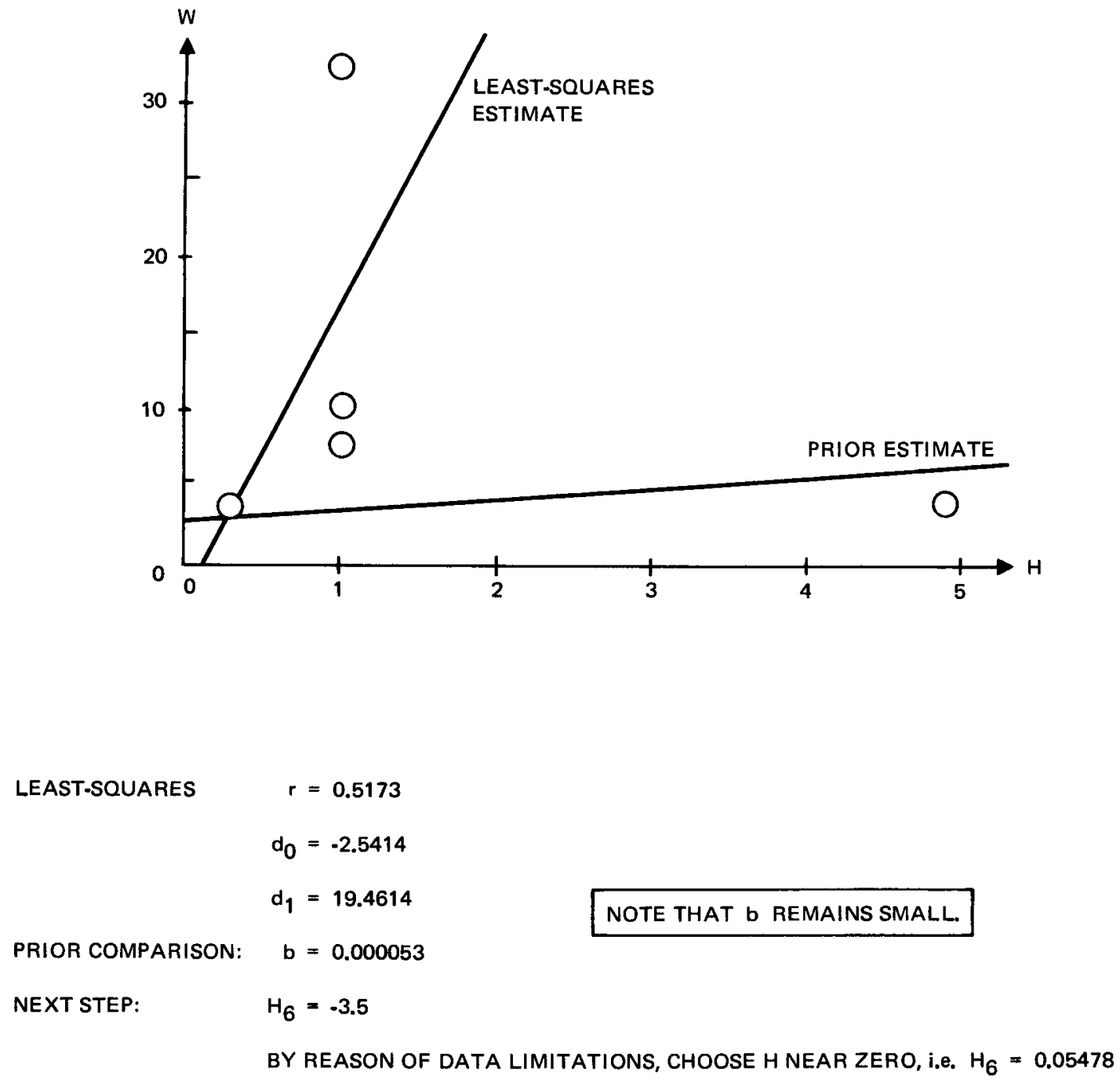

Figure B-5. Third Stage (5 points)

LMEC -69-8 


$\begin{array}{ll}H_{1}=1.00 & W_{1}=10.31 \\ H_{2}=4.89 & w_{2}=4.93 \\ H_{3}=0.313 & W_{3}=3.55 \\ H_{4}=1.00 & W_{4}=32.5 \\ H_{5}=1.00 & W_{5}=7.95 \\ H_{6}=0.05478 & W_{6}=2.14\end{array}$
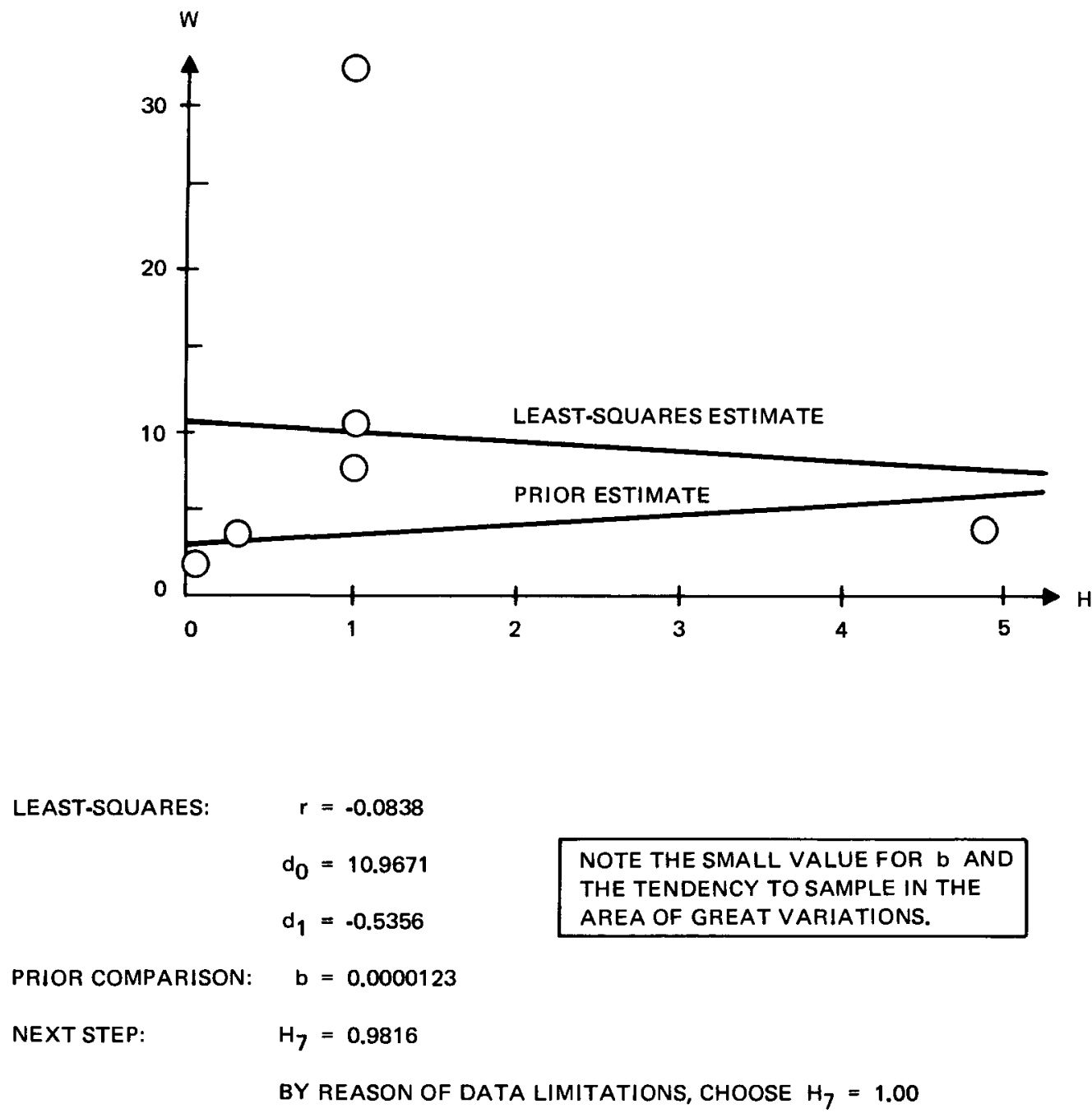

Figure B-6. Fourth Stage ( 6 points) 


$$
\begin{array}{ll}
H_{1}=1.00 & W_{1}=10.31 \\
H_{2}=4.89 & W_{2}=4.93 \\
H_{3}=0.313 & W_{3}=3.55 \\
H_{4}=1.00 & W_{4}=32.5 \\
H_{5}=1.00 & W_{5}=7.95 \\
H_{6}=0.05478 & W_{6}=2.14 \\
H_{7}=1.00 & W_{7}=20.0
\end{array}
$$

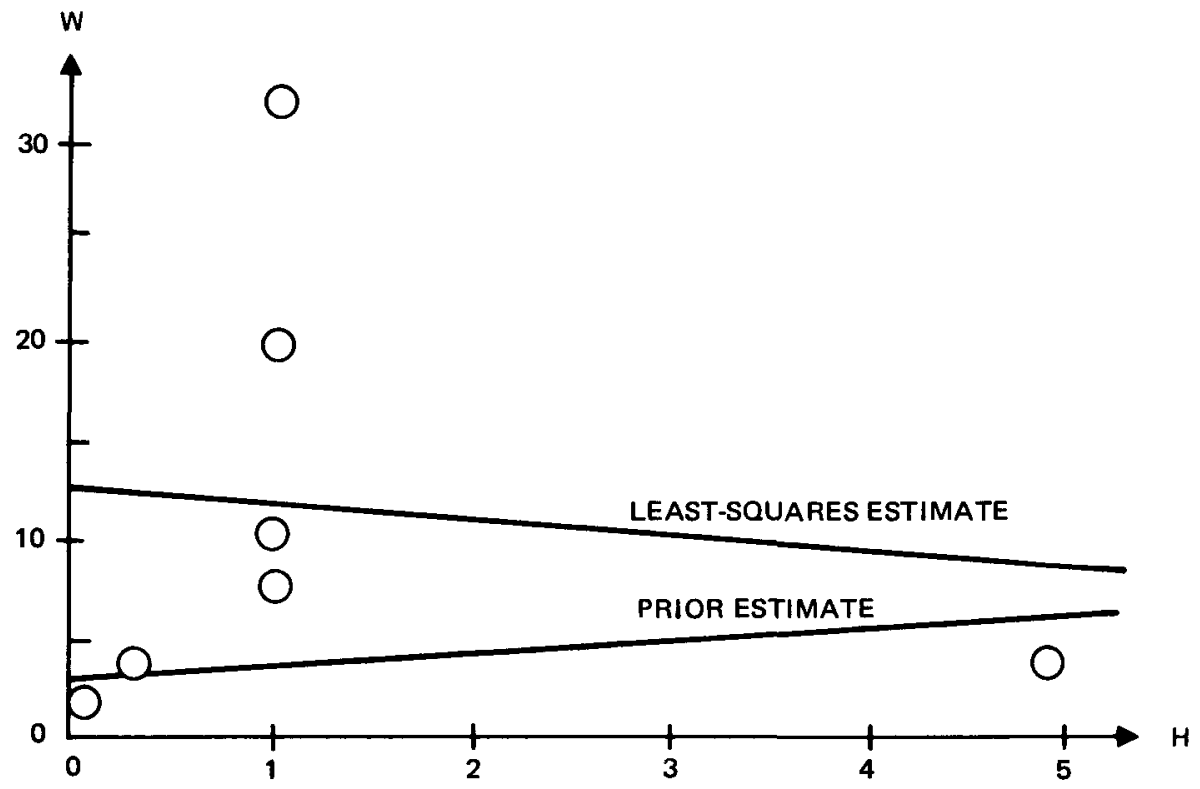

$$
\text { LEAST-SOUARES: } \quad \begin{aligned}
r & =-0.1081 \\
\mathrm{~d}_{0} & =12.5929 \\
\mathrm{~d}_{1} & =-0.7313
\end{aligned}
$$

PRIOR COMPARISON:

$$
b=0.0000067
$$

NEXT STEP:

$H_{8}=0.9813$

BY REASON OF DATA LIMITATIONS, CHOOSE $H_{8}=1.00$

Figure B-7. Fifth Stage (7 points)

LMEC-69-8 


$$
\begin{array}{ll}
H_{1}=1.00 & W_{1}=10.31 \\
H_{2}=4.89 & W_{2}=4.93 \\
H_{3}=0.313 & W_{3}=3.55 \\
H_{4}=1.00 & W_{4}=32.5 \\
H_{5}=1.00 & W_{5}=7.95 \\
H_{6}=0.05478 & W_{6}=2.14 \\
H_{7}=1.00 & W_{7}=20.0 \\
H_{8}=1.00 & W_{8}=9.44
\end{array}
$$

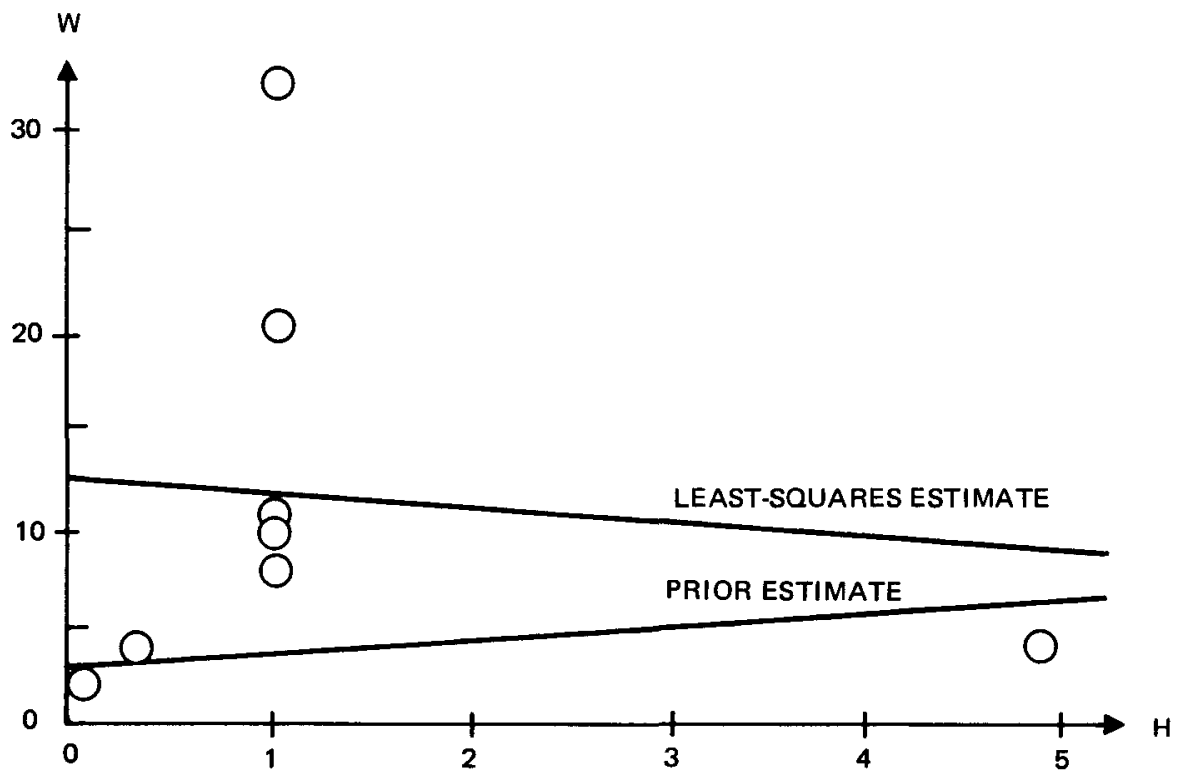

LEAST-SQUARES:

$$
\begin{aligned}
r & =-0.1018 \\
d_{0} & =12.2349 \\
d_{1} & =-0.6882
\end{aligned}
$$$$
\text { OBSERVE HOW } \mathrm{H}_{9} \text { IS CHOSEN NEAR }
$$$$
\text { POINTS HAVING LARGE UNCERTAINTY. }
$$

PRIOR COMPARISON: $\quad b=0.0000139$

NEXT STEP: $\quad H_{9}=0.9841$

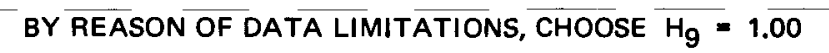

Figure B-8. Sixth Stage (8 points)

LMEC -69-8 


$\begin{array}{ll}H_{1}=1.00 & W_{1}=10.31 \\ H_{2}=4.89 & w_{2}=4.93 \\ H_{3}=0.313 & w_{3}=3.55 \\ H_{4}=1.00 & W_{4}=32.5 \\ H_{5}=1.00 & W_{5}=7.95 \\ H_{6}=0.05478 & W_{6}=2.14 \\ H_{7}=1.00 & W_{7}=20.0 \\ H_{8}=1.00 & W_{8}=9.44 \\ H_{9}=1.00 & W_{9}=8.76\end{array}$

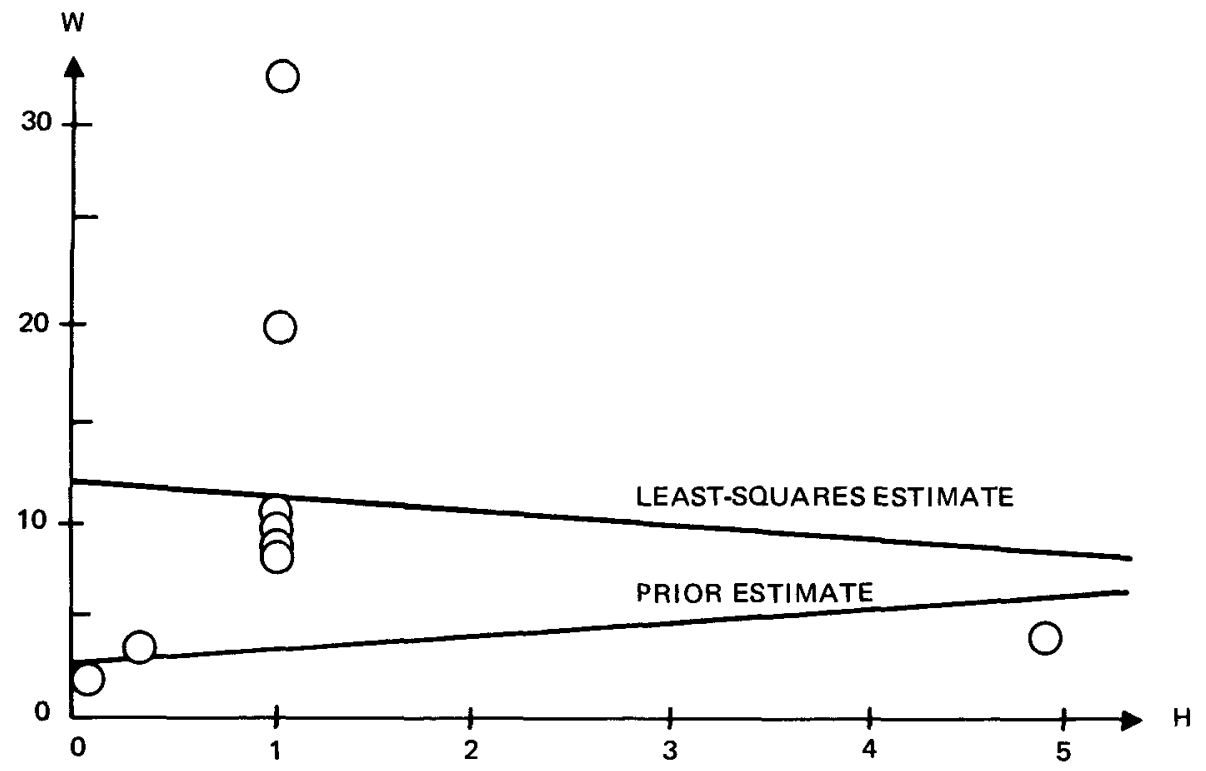

$\begin{array}{rlrl} & \text { LEAST-SQUARES: } & r & =-0.0951 \\ & d_{0}=11.8704 \\ d_{1} & =-0.6443 \\ \text { PRIOR COMPARISON: } & b & =0.0000022 \\ \text { NEXT STEP: } & H_{10} & =0.9864\end{array}$

NOTE THAT SAMPLING IS CONTINUED NEAR $H=1$, WHERE THE VALUES OF W DISPLAY LARGE FLUCTUATIONS.

Figure B-9. Seventh Stage (9 points)

LMEC -69-8 
For the case that $\mathrm{H}$ is known to be a normal random variable and that the relationship between $\mathrm{H}$ and $\mathrm{W}$ is truly linear, conventional statistical methods may be used. Consider the representation,

$$
\mathrm{W}=\alpha+\beta \mathrm{H} .
$$

The mathematical theory of statistics shows that if $\mathrm{H}$ and $\mathrm{W}$ are normal random variables, then $\alpha$ is a normal random variable and $\beta$ follows a t-distribution. If more data were to be collected with as much variation as the nine points given in the example and if the respective probabilities that $\alpha=3$ and $\beta=2 / 3$ were evaluated, these probabilities would be very small.

In summary, it appears that this Bayesian method, although admittedly somewhat primitive, could be a useful extension to conventional statistical methods. The viewpoint that the experimental outcome is the sum of the (true) deterministic variable to which a random (noise) variable has been added is rather general and amenable to wide variety of environments when the noise is assumed to be Weibull-distributed. In this manner, experimental errors of Gaussian, exponential, Rayleigh, or gamma density can be conveniently identified. 
○

○ 


\section{REFERENCES}

1. M. Sasieni, A. Yaspan, and L. Friedman, Operations Research-Methods and Problems (John Wiley and Sons, New York, 1959), p 42

2. J. D. Wilde, Optimum Seeking Methods (Prentice-Hall, 1960)

3. J. M. Juran, Quality Control Handbook (McGraw-Hill, 1951)

4. C. E. Shannon, The Mathematical Theory of Communication (Univ. of Illinois Press, 1949)

5. A. Rényi, "On Measures of Entropy and Information," Fourth Berkeley Symposium on Mathematical Statistics and Probability, June 20-July 30, 1960 (Univ. of Calif. Press, 1961 )

6. D. V. Lindley, "On a Measure of Information Provided by an Experiment," Ann. Math. Stat., 27, p 986-1005 (1956)

7. G. B. Wetherill, Sequential Methods in Statistics (John Wiley and Sons, New York, 1966)

8. O. L. Davies, ed., Design and Analysis of Industrial Experiments (Hafner, 1956)

9. J. E. Walsh, Handbook of Non-Parametric Statistics, Vol. I (Van Nostrand, 1962) p $228-275$

10. H. Raiffa and R. Schlaifer, Applied Statistical Decision Theory (Harvard Univ. Press, Boston, 1961) p 29

11. Ibid., p 53

12. R. Schulhof and D. L. Lindstrom, "Application of Bayesian Statistics in Reliability," paper presented to American Institute of Aeronautics and Astronautics, Los Angeles, February 23, 1967

13. J. R. Rutherford and R. G. Krutchkoff, "The Empirical Bayes Approach: Estimating the Prior Distribution," Biometrika, 54, p 326-328 (1967)

14. R. L. Kashyap and C. C. Blaydon, "Estimation of Probability Density and Distribution Functions, "IEEE Trans. Info. Theory, Vol 17-14, No.4, p 549-555, July 1968

15. E. Parzen, "Estimation of Probability Density Function and Mode," Ann. Math. Stat., 33, p $1065-1076$ (1962

16. M. H. Hammond, Jr., "Optimum Finite Sequential Pattern Recognition Using the Maximum Principle of Pontryagin," Columbus Div., North American Rockwell Corporation Report No. NR68-H-203 
0

0 


\section{BIBLIOGRAPHY}

Abramowitz, M., and Stegun, I. A., editors, Handbook of Mathematical Functions, NBS Applied Math Series 55 (U.S. Government Printing Office, 1965)

Acton, F. S., Analysis of Straight-Line Data (John Wiley and Sons, New York 1959)

Albert, A. E., and Garner, L. A., Jr., Stochastic Approximation and NonLinear Regression (MIT Press, 1967)

Ando, A., and Kaufman, G., "Bayesian Analysis of the Independent MultiNormal Process - Neither Mean nor Precision Known," JASA, 60, No.309, p 347-358 (March 1965)

Aoki, M., Optimization of Stochastic Systems (Academic, 1967)

ASME, Proceedings of the Seventh Reliability and Maintainability Conference, San Francisco, July 14-17, 1968, ASME (1968)

Barnard, G. A., "The Frequency Justification of Certain Sequential Tests," Biometrika, 59, p 144-150 (1952)

Bellman, R. E., "A Mathematical Formulation of Variational Processes of Adaptive Type," Proceedings of the Fourth Berkeley Symposium on Mathematical Statistics and Probability, June 20-July 30, 1960 (Univ. of Calif. Press, 1961)

Bellman, R. E., Adaptive Control Processes: A Guided Tour (Princeton, 1961)

Bellman, R. E., Dynamic Programming (Princeton, 1957)

Bellman, R. E., and Dreyfus, S. F., Applied Dynamic Programming (Princeton, 1962)

Bhattacharya, S. K., "Bayesian Approach to Life Testing and Reliability Estimation," JASA, 62, No.317, p 48-62 (March 1967)

Bicking, C. A., "Some Uses of Statistics in the Planning of Experiments," Industrial Quality Control, 10, No.4, p 23 (Jan. 1954)

Birnbaun, A., "Sequential Tests for Variance Ratios and Components of Variance," Ann. Math. Stat., 29, p 504-514 (1958)

Blā $\bar{c}$ we11, D., "Equivalent Comparisons of Experiments,"Ann. Math. Stat., 24, p 265-272 (1953)

Blackwell, D., and Girshick, M. A., Theory of Games and Statistical Decisions (John Wiley and Sons, New York, 1954) 
Box, G.E.P., Time Series, Forecasting and Control (Holden-Day, 1968)

Box, G.E.P., and Draper, N. R., "A Basis for the Selection of a Response Surface Design," JASA, 54, p 622-654 (1959)

Box, G.E.P., and Hunter, J. S., "Multifactor Experimental Designs for Exploring Response Surfaces," Ann. Math. Stat., 28, No. 1, p 195-241 (March 1957)

Box, G.E.P., and Tiao, G. C., "Multiparameter Problems from a Bayesian Point of View," Ann. Math. Stat., 36, p 1468-1482 (1965)

Box, G.E.P., and Tiao, G. C., "A Bayesian Approach to the Importance of As sumptions Applied to the Comparison of Variances," Biometrika, 51, p 153-167(1964)

Box, G.E.P., and Tiao, G. C., "A Further Look at Robustness via Bayes" Theorem," Biometrika, 49, p 419-432 (1962)

Brooks, S., and Mickey, M. R., "Optimum Estimation of Gradient Direction in Steepest Ascent Experiments," Biometrics, 17, p 48-56 (1961)

Chernoff, H., "Sequential Design of Experiments," Ann. Math. Stat., 30, p 755-770 (1959)

Chernoff, H., "Sequential Tests for the Mean of a Normal Distribution," Proceedings of the Fourth Berkeley Symposium on Mathematical Statistics and Probability, June 20-July 30, 1960 (Univ. of Calif. Press, 1961)

Connors, M. M., and Teichroew, D., Optimal Control of Dynamic Operations Research Models (International Textbook, Scranton, Pa., 1967)

Cornfield, J., "A Bayesian Test of Some Classical Hypotheses," JASA, 61, p $577-594$ (Sept. 1966)

Davies, O. L., ed., Design and Analysis of Industrial Experiments (Hafner, 1956)

DeBush, R. E., "Experience in Evolutionary Operations at Tennessee Eastman Company," Industrial Quality Control, p 15-21 (Oct. 1962)

Deutsch, R., Estimation Theory (Prentice-Hall, 1965)

Draper, N. P., "Ridge Analysis of Response Surfaces," Technometrics, 5, p 649-479 (1963)

Finney, D. J., Experimental Design and Its Statistical Basis (Univ. of Chicago Press, 1955)

Geisser, S., "Bayesian Estimation in Multivariate Analysis," Ann. Math. Stat., 60 p I50-159 (March 1965)

LMEC-69-8 
Gelfand, I. M., and Fomin, S. U., Calculus of Variations (Prentice-Hall, 1963)

Good, I. J., The Estimation of Probabilities (MIT Press, 1965)

Good, I. J., Probability and the Weighing of Evidence (Hafner, 1950)

Hald, A., Statistical Theory with Engineering Applications (John Wiley and Sons, New York, 1952)

Hall, W. J., Wissman, R. A., and Ghosh, J. K., "The Relationship Between Sufficiency and Invariance with Applications in Sequential Analysis, "Ann.

Math. Stat., 36, p 575-614 (1965)

Hammond, M. H., Jr., "Optimum Finite Sequential Pattern Recognition Using the Maximum Principle of Pontryagin," Columbus Div., North American Rockwell Report No. NR68-H-203

Hammond, M. H., Jr., and Weed, H. R., "Determination of the Optimal Measurement Sequence for a Noisy Pattern Recognition System via the Discrete Maximum Principle," paper delivered at Fourth Congress of International Federation of Automatic Control, Warsaw, June 16-21, 1969

Harrington, E. C., Jr., "A Procedure for Sequential Experimentation," Chemical Engineering Progress Symposium Series, Vol. 59, No. 42, American Institute of Chemical Engineers, 1963, p 1-7

Hartigan, J., "Invarient Prior Distributions," Ann. Math. Stat., 35, p 836-845 (1964)

Hildreth, C., "Bayesian Statisticians and Remote Clients," Econometrika, 32 , p $422-438$ (1963)

Ho, Y. C., and Lee, R. C.K., "A Bayesian Approach to Problems on Stochastic Estimation and Control," IEEE Trans. Auto. Cont., AC-9, p 333-339 (Oct. 1964)

Howard, R. A., "Bayesian Decision Models for System Engineering," IEEE Trans. on System Sci. and Cybernetics, Vol SSC-1, No. 1, p 36-40 (Nov. 1965)

Howard, R. A., Dynamic Programming and Markov Processes (MIT Press, 1960)

IBM, Technical Publications Dept., 112 E. Post Road, White Plains 10601 , System/360 Scientific Subroutine Package Programmers' Manual, IBM 1968

Ivakhenenko, A. G., and Lapa, V. G., Cybernetics and Forecasting Techniques (American-Elsevier, 1967)

Jeffreys, J., Theory of Probability (3rd Ed., Clarendon Press, Oxford, 1961)

Johnson, N. L., "Sequential Procedures in Certain Components of Variance Problems," Ann. Math. Stat., 25, p 357-366 (1954) 
Juran, J. M., Quality Control Handbook (McGraw-Hill, 1951)

Kalman, R. E., "A New Approach to Linear Filtering and Prediction Problems," ASME Trans., Vo1.82D, March 1960

Kashyap, R. L., and Blaydon, C. C., "Estimation of Probability Density and Distribution Functions, "IEEE Trans. Info. Theory, Vol. 17-14, No.4, p 549-555 (July 1968)

Kiefer, J., "Optimum Experimental Designs V, with Applications to Systematic and Rotatable Designs," Fourth Berkeley Symposium on Mathematical Statistics and Probability, June 20-July 30, 1960 (Univ. of Calif. Press, 1961)

Lee, R.C.K., Optimum Estimation, Identification and Control (MIT Press, 1964)

Leitmann, C., ed., Optimization Techniques (Academic, 1963)

Lindley, D. V., Introduction to Probability and Statistics from a Bayesian Viewpoint (Cambridge Univ. Press, 1965)

Lindley, D. V., "On a Measure of Information Provided by an Experiment," Ann. Math. Stat., 27, p 986-1005 (1956)

Linnik, Y. V., Method of Least Squares and Principles of the Theory of Observations (Pergamon, 1961)

Lloyd, D. K., and Lipow, M., Reliability: Management, Methods and Mathematics (Prentice-Hall, 1962)

MacFarland, W. J., "Use of Bayes Theorem in its Discrete Formulation for Reliability Estimation Purposes," Ann. Assurance Sci., Seventh Reliability and Maintainability Conference, 1968, p 352-365

Mann, N. R., "Point and Interval Estimation Procedures for the TwoParameter Weibull and Extreme-Value Distributions," Technometrics, 10, No. 2, p 231-256 (May 1968)

Martin, J. J., Bayesian Decision Problems and Markov Chains (John Wiley and Sons, New York, 1967)

Mosier, C. I., "On the Reliability of a Weighted Composite," Psychometrika, 8 , p $161-168$ (1943)

Neyman, J., ed., Proceedings of the Fourth Berkeley Symposium on Mathematical Statistics and Probability, June 20-July 30, 1960 (Univ. of Calif. Press, 1961)

Nilsson, N. J., Leaning Machines, Foundations of Trainable PatternClas sifying Systems (McGraw-Hill, 1965)

Papoulis, A., Probability, Random Variables and Stochastic Processes (McGraw-Hill, 1965) 
Parzen, E., Estimation of Probability Density Function and Mode," Ann. Math. Stat., 33, p 1065-1076 (1962)

Parzen, Emanuel, Stochastic Processes (Holden-Day, 1962)

Peterson, E. L., Statistical Analysis and Optimization of Systems (John Wiley and Sons, New York, 1961)

Pontryagin, L. S., et a1., The Mathematical Theory of Optimal Processes, Interscience, $1962, \mathrm{p} 683$

Rabinowicz, E., Friction and Wear of Materials (John Wiley and Sons, New York, 1965)

Raiffa, H., and Schlaifer, R., Applied Statistical Decision Theory (Harvard Univ. Press, Boston, 1961) p 29, 53

Rényi, A., "On Measures of Entropy and Information," Fourth Berkeley Symposium on Mathematical Statistics and Probability, June 20-July 30, p 547-561 (Univ. of Calif. Press, 1961)

Richardson, J. M., North American Rockwell Science Center, personal communication

Robbins, H., "An Empirical Bayes Approach to Statistics," Third Berkeley Symposium on Mathematical Statistics and Probability (Univ. of Calif. Press, 1956)

Robbins, H. , "Some Aspects of the Sequential Design of Experiments," Bull. Amer. Math. Soc., 58, 1952, p 527-536

Rutherford, J. P., "Foundations of Empirical Bayes," Address to 128 th Annual Meeting, American Statistical Association, Toronto, August 21, 1968

Rutherford, J. R., and Krutchkoff, R. G., "The Empirical Bayes Approach: Estimating the Prior Distribution," Biometrika, 54, p $326-328$ (1967)

Rutherford, J. R., "The Empirical Bayes Approach: Estimating Posterior Quantiles," Biometrika, 54, p 672-675 (1967)

Sasieni, M., Yaspan, A., and Friedman, L., Operations Research - Methods and Problems (John Wiley and Sons, New York, 1959) p 42

Savage, L. J., The Foundations of Statistics (John Wiley and Sons, New York, 1954)

Schulhof, R., and Lindstrom, D. L., "Application of Bayesian Statistics in Reliability," paper presented to American Institute of Aeronautics and Astronautics, Los Angeles, February 23, 1967

Schum, D. A., Goldstein, I. L., and Southard, J. F., "Research on a Simulated Bayesian Information-Processing System," IEEE Trans. on Human Factors, March 1966, p 37 
Shannon, C. E., The Mathematical Theory of Communication (Univ. of Illinois Press, 1949)

Spragins, J., "A Note on the Iterative Application of Bayes 'Rule, "IEEE Trans. on Info. Theory, Vol. IT-11, No.4 (Oct. 1965)

Sworder, D. Optimal Adaptive Control Systems (Academic, 1966)

Wald, A., Statistical Decision Functions (John Wiley and Sons, New York, 1950)

Wald, A., Sequential Analysis (John Wiley and Sons, New York, 1947)

Wald, A., "On the Efficient Design of Statistical Investigations," Ann. Math. Stat., 14, p 134-140 (1943)

Walsh, J. E., Handbook of Non-parametric Statistics, Vol. I (Van Nostrand, 1962) p 228-275

Weiler, H., "The Use of Incomplete Beta Functions for Prior Distributions in Binomial Sampling, "Technometrics, 7, p 335-347 (1965)

Wetherill, G. B., Sequential Methods in Statistics (John Wiley and Sons, New York, 1966)

Wilde, J. D., Optimum Seeking Methods (Prentice-Hall, 1960)

Winder, B. J., Statistical Principles in Experimental Design (McGraw-Hill, 1962)

Winkler, R. L., "The Assessment of Prior Distributions in Bayesian Analysis," JASA, 62, p 776 (1967)

Wolberg, J. R., Prediction Analysis (Van Nostrand, 1967) 